\begin{tabular}{|c|c|}
\hline Title & Favorable Conditions for Suspension Freezing in an A rctic Coastal Polynya \\
\hline Author(s) & $\begin{array}{l}\text { Ito, Masato; Ohshima, Kay I; Fukamachi, Y asushi; Hirano, Daisuke; Mahoney, A ndrew R.; Jones, Joshua; Takatsuka, } \\
\text { Toru; Eicken, Hajo }\end{array}$ \\
\hline Citation & $\begin{array}{l}\text { Journal of Geophysical Research Oceans, 124(12), 8701-8719 } \\
\text { https://doi.org/10.1029/2019JC015536 }\end{array}$ \\
\hline Issue Date & 2019-11-29 \\
\hline Doc URL & http:/hdl.handle.net/2115//8371 \\
\hline Rights & Copyright 2019 A merican Geophysical Union. \\
\hline Rights(URL) & https://creativecommons.org/icenses/by/4.0/ \\
\hline Type & article \\
\hline File Information & Journal of Geophysical Research Oceans_124_12_8701-8719.pdf \\
\hline
\end{tabular}

Instructions for use 


\author{
RESEARCH ARTICLE \\ 10.1029/2019JC015536 \\ Key Points: \\ - ADCP data provided evidence of \\ frazil ice penetrating to $\sim 25 \mathrm{~m}$ in the \\ water column during supercooling \\ episodes in a coastal polynya \\ - The combination of acoustic and \\ optical measurements revealed \\ underwater frazil ice-sediment \\ interaction at water depths of 10-25 \\ $\mathrm{m}$ \\ - Suspension freezing can often occur \\ in shallow polynyas and is suggested \\ to be the dominant process of \\ sediment incorporation into sea ice
}

Correspondence to:

M. Ito,

itoh-m@ees.hokudai.ac.jp

Citation:

Ito, M., Ohshima, K. I., Fukamachi, Y., Hirano, D., Mahoney, A. R., Jones, J., et al. (2019). Favorable conditions for suspension freezing in an Arctic coastal polynya. Journal of Geophysical Research: Oceans, 124, 8701-8719. https://doi.org/10.1029/2019JC015536

Received 30 JUL 2019 Accepted 23 NOV 2019 Accepted article online 29 NOV 2019 Published online 8 DEC 2019

(C)2019. American Geophysical Union. All Rights Reserved.

\section{Favorable Conditions for Suspension Freezing in an Arctic Coastal Polynya}

\author{
Masato Ito ${ }^{1}$, Kay I. Ohshima ${ }^{1,2}$, Yasushi Fukamachi ${ }^{1,2,3}$, Daisuke Hirano ${ }^{1}$, Andrew R. Mahoney ${ }^{3,4}$, \\ Joshua Jones $^{4}$, Toru Takatsuka ${ }^{1}$, and Hajo Eicken ${ }^{3,5}$ \\ ${ }^{1}$ Institute of Low Temperature Science, Hokkaido University, Sapporo, Japan, ${ }^{2}$ Arctic Research Center, Hokkaido \\ University, Sapporo, Japan, ${ }^{3}$ Global Station for Arctic Research, Global Institution for Collaborative Research and \\ Education, Hokkaido University, Sapporo, Japan, ${ }^{4}$ Geophysical Institute, University of Alaska Fairbanks, Fairbanks, AK, \\ USA, ${ }^{5}$ International Arctic Research Center, University of Alaska Fairbanks, Fairbanks, AK, USA
}

\begin{abstract}
Arctic sea ice incorporates and transports sediment, releasing it back into the water column during the melting season. This process constitutes an important aspect of marine sediment transport and biogeochemical cycling. Sediment incorporation into sea ice is considered to occur mainly through underwater interaction between frazil ice and resuspended sediment, referred to as suspension freezing. However, harsh environmental conditions have greatly limited field observations of this phenomenon. Analysis of mooring data from a coastal polynya in the northeastern Chukchi Sea, in conjunction with coastal ice radar and meteorological data, indicates that suspension freezing is a key mechanism for sediment entrainment into sea ice. During polynya episodes, acoustic backscatter data obtained by an Acoustic Doppler Current Profiler showed the presence of frazil ice from the surface down to 20- to 25-m depth, coinciding with in situ and potential supercooling. Underwater frazil ice persisted over 1 week under windy, turbulent water column conditions. A combination of the turbidity and Acoustic Doppler Current Profiler backscatter data revealed upward sediment dispersion associated with strong currents during the polynya episodes. The fact that frazil ice and resuspended sediment were detected at the same depth and time strongly suggests the interaction between ice crystals and sediment particles, that is, suspension freezing.
\end{abstract}

Plain Language Summary Sea ice incorporates, transports, and releases particulate matter. These processes constitute an important aspect of the biology, biogeochemical cycling, and pollutant transport in polar oceans. Seafloor sediments serve as the most important source of such particulate matter; however, the process of sediment incorporation into sea ice remains poorly explored. We conducted a year-long study of sediment resuspension and entrainment processes, using underwater sensors deployed in the Chukchi Sea. During winter, wind-driven offshore transport of sea ice created area of open water and newly grown thin ice that persisted for several days, so-called coastal polynya or flaw lead system. Our sensors recorded small ice crystals, so-called frazil ice, that formed in the water column when water temperatures were below freezing point (supercooling). During some of these episodes, sediment was resuspended from the seafloor and dispersed upward by the strong currents, bringing it into water depths at which frazil ice was encountered. Such conditions provide for opportunities that allow frazil ice crystals or aggregates to capture resuspended sediment, a process referred to as suspension freezing. Based on this study, we propose that suspension freezing commonly occurs in shallow Arctic polynyas, serving as a key process of sediment incorporation into sea ice.

\section{Introduction}

Sediment-laden sea ice, also referred to as dirty ice, is a common occurrence throughout coastal and offshore regions in the Arctic Ocean (Darby et al., 2011; Eicken et al., 1997, 2005, 2000; Nürnberg et al., 1994; Osterkamp \& Gosink, 1984). Seafloor sediments are considered to be the dominant source of this entrained particulate matter (Measures, 1999; Lannuzel et al., 2010, 2014; Dethleff \& Kuhlmann, 2009, 2010; Darby et al., 2011). Sediment incorporated into sea ice is transported with ice drift and released into the ocean during ice melt. These processes contribute significantly to sediment deposition and redistribution, dispersal of pollutants, and transport of organic carbon (Cooper et al., 1998; Eicken et al., 2005; Pfirman et al., 1995; Sakamoto et al., 2005). In addition, sediment transport by sea ice affects biological and biogeochemical processes. For example, in sea ice regions, massive phytoplankton blooms have been found to occur during 
periods of sea ice retreat (Arrigo et al., 2012, 2014; Arrigo \& McClain, 1994; Arrigo \& van Dijken, 2004; Mundy et al., 2009; Mustapha \& Saitoh, 2008; Nihashi et al., 2012). Micronutrients such as iron originating from particulate matter inside sea ice are possible triggers of such blooms (Dieckmann et al., 1991; Kanna et al., 2014; Sedwick \& DiTullio, 1997). Sediment transported by sea ice as well as icebergs, referred to as ice rafted debris, has deposited on the seafloor over millions of years (e.g., Polyak et al., 2010; Tremblay et al., 2015). Such ice-rafted debris can serve as a useful proxy for paleo-oceanographic and paleo-climate reconstructions.

In turbulent open water conditions, initial sea ice formation occurs in the form of small disk-shaped or dendritic crystals, millimeter to centimeter in size, so-called frazil ice (Martin, 1981). Frazil ice, formed in the upper water column, gradually accumulates at the surface, forming so-called grease ice. Grease ice, a mixture of interlocking frazil crystals and seawater, creates a soupy layer at the surface, suppressing incident waves and swells efficiently (Martin \& Kauffman, 1981). With continued heat loss to the atmosphere, it eventually consolidates into granular ice, forming a solid ice sheet and ice floes. Laboratory experiments (Kempema et al., 1993; Reimnitz et al., 1993; Smedsrud, 2001) and numerical model simulations (Sherwood, 2000; Smedsrud, 2002) indicate that sedimentary particles are incorporated into sea ice through interaction with frazil and/or grease ice in the water column. Physical retention and surface adhesion of sediment particles along with aggregation of frazil crystals, referred to as suspension freezing (Campbell \& Collin, 1958), lead to sediments firmly encased in solid sea ice. Field measurements in the Arctic Ocean reported that sediment concentration inside granular ice layers are far higher than that inside columnar ice layers (e.g., Eicken et al., 2000, 2005; Osterkamp \& Gosink, 1984; Stierle \& Eicken, 2002). This fact implies that suspension freezing is the major process of sediment incorporation into sea ice. However, in situ observations of suspension freezing have been hampered by harsh conditions in sea ice regions.

Suspension freezing is considered to occur mainly during fall freeze-up of shallow water regions (Campbell \& Collin, 1958; Eicken et al., 1997; Reimnitz et al., 1992) and throughout the ice growth season in coastal polynyas (e.g. Eicken et al., 2005; Dethleff \& Kuhlmann, 2009, 2010). Coastal polynyas are of particular importance for sediment entrainment because (1) sea ice production is quite high over winter, (2) frazil ice can form in the water column as a result of wind and thermohaline mixing, (3) water depth is shallow, and hence, (4) frazil ice can easily interact with resuspended sediment. Regarding the second point, laboratory studies showed that supercooled denser seawater formed through intense cooling under turbulent conditions sinks to depth and allow for frazil ice formation deeper in the water column (Smedsrud, 2001; Ushio \& Wakatsuchi, 1993). This type of ice formation process has been directly observed in several Arctic coastal polynyas (Dmitrenko et al., 2010; Drucker et al., 2003; Ito et al., 2015; Skogseth et al., 2009).

Field measurements indicate that the acoustic backscatter strength data obtained from Acoustic Doppler Current Profilers (ADCP) can be utilized to detect frazil ice in the water column (Dmitrenko et al., 2010; Ito et al., 2017; Leonard et al., 2006; Richard et al., 2011). Although ADCPs are normally employed to observe the vertical profile of the current, they also provide a measure of acoustic backscatter strength and its enhancement in the presence of underwater frazil ice. The ADCP backscatter data have been also used to detect resuspended sediment in shallow water regions such as coral reefs and rivers (e.g., Hoitink, 2004). These findings point to potential utility of ADCP backscatter data to detect suspension freezing. Additional support for this approach comes from ADCP observations that suggest occurrence of suspension freezing along with pack ice edge off northeast Sakhalin in the Sea of Okhotsk at a water depth of 100 m (Ito et al., 2017). To the best of our knowledge, this latter study is the only report that may indicate suspension freezing from the field measurements, 60 years after Campbell and Collin (1958) first proposed the mechanism in their study of the Foxe Basin in the Canadian Arctic. Thus, we recognize the need for a more systematic, in-depth assessment of key processes involved in sediment incorporation into sea ice, drawing on observations in polynya regions.

The coastal polynya system of the northeastern Chukchi Sea along the Alaskan coast, with significant winddriven offshore ice transport, has been identified as a major source of ice production (Martin et al., 2004, 2005; Tamura \& Ohshima, 2011; Iwamoto et al., 2014; Figure 1). Saline water, that is, brine, excluded from growing sea ice in these polynyas results in dense water, which contributes to formation of the cold halocline layer in the Arctic Ocean (Hirano et al., 2018; Itoh et al., 2012; Martin et al., 2004). Previous work, tracing back highly sediment laden ice based on ice drift trajectories from buoys and a simple model, indicates significant particle entrainment into sea ice in this region (Eicken et al., 2005). Here we analyze data from 

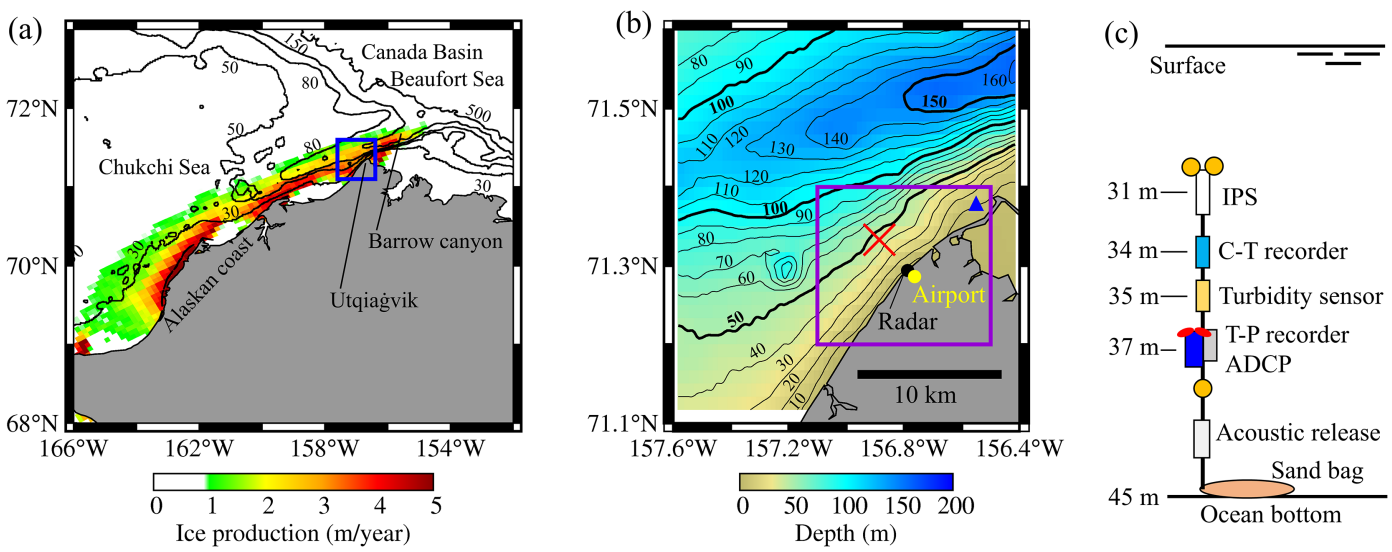

Figure 1. (a) Annual cumulative ice production in the northeastern Chukchi Sea over 2003-2011, estimated from Advanced Microwave Scanning Radiometer-Earth Observing System (AMSR-E) data (Iwamoto et al., 2014). The 30-, 50-, 80-, 150-, and 500-m isobaths derived from the General Bathymetric Chart of the Ocean (GEBCO) are also shown. The blue rectangle denotes the region of Figure 1b. (b) Bathymetry around the study area based on GEBCO. The red cross denotes the mooring location. The black and yellow circles denote the sea ice radar and airport. The blue triangle denotes the sea ice core site. The purple rectangle indicates the area of the radar imagery shown in Figure 2. (c) The schematics diagram of the oceanographic mooring. The values at the left side of the instruments denote nominal depths.

oceanographic moorings deployed in a collaboration between Hokkaido University and University of Alaska Fairbanks since 2009 in the northernmost stretch of this polynya system, off Utqiagivik, Alaska (previously called Barrow).

From late fall through spring, landfast sea ice persists just off the coast around Utqiagivik (Figure 2; Mahoney, Eicken, Gaylord, \& Shapiro, 2007, Mahoney, Eicken, \& Shapiro, 2007, Mahoney et al., 2014; Druckenmiller et al., 2009; Jones et al., 2016). When southeasterly winds move the ice pack offshore, a polynya or flaw lead forms beyond the landfast ice edge. Underwater frazil ice formation associated with supercooling sometimes occurs in the polynya (Ito et al., 2015). Drawing on mooring data, complemented by observations from a coastal ice radar and weather station data at Utqiagivik, we aim to examine in detail the oceanographic, sea ice, and meteorological conditions conductive to suspension freezing and sediment entrainment into the ice cover.

\section{Data and Methods}

\subsection{Mooring Data}

This study is based on mooring data obtained in 2014-2015. The mooring was deployed $\sim 5 \mathrm{~km}$ offshore at $71.333^{\circ} \mathrm{N}, 156.866^{\circ} \mathrm{W}$ in $45-\mathrm{m}$ water depth on 3 August 2014 (local time) and recovered on 5 August 2015.
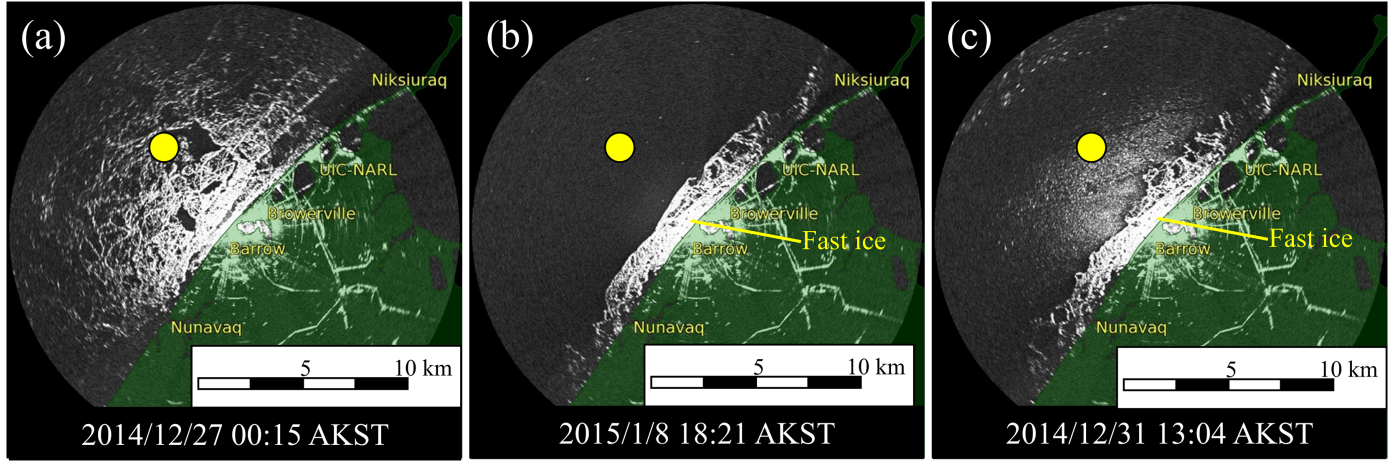

Figure 2. Sea ice radar imageries at (a) 00:15 h on 27 December 2014, (b) 18:21 h on 8 January 2015, and (c) 13:04 h on 31 December 2014. White indicates high radar backscatter. Yellow circles denote the mooring site. Figures 2a-2c show typical examples of the three categories of ice cover, open water, and frazil ice cases, respectively. 
The mooring was equipped with an Ice-Profiling Sonar (IPS: ASL Environmental Science, IPS5 $420 \mathrm{kHz}$ ), a conductivity-temperature recorder (C-T recorder: SeaBird, SBE-37), a turbidity-chlorophyll sensor (turbidity sensor: JFE Advantec, INFINITY-CLW), an ADCP (RD Instruments, Workhorse Sentinel $300 \mathrm{kHz}$ ), and a temperature-pressure recorder (T-P recorder: SeaBird, SBE-39) at 31, 34, 35, 37, and $37 \mathrm{~m}$ in nominal depths, respectively (Figure 1c). Hereafter, we use these nominal depths to express the instrument depths in the water column.

An IPS measures the distance between the transducer and the ocean surface or ice bottom from the travel time of the acoustic ping (range data). The wavelength of a single pulse was $0.1 \mathrm{~m}$, resulting in an error of at least $\pm 0.05 \mathrm{~m}$ for range data. Sea ice draft was estimated from the range data using the software supplied by ASL Environmental Science. The IPS obtained the range data every $1 \mathrm{~s}$. This study used ice draft data coincident with the ADCP measurement, at intervals of 15 min. Ice thickness, $h_{i}$, was estimated from ice draft, $h_{d}$, as $h_{i}=1.1 \times h_{d}$. The details of the IPS data processing are found in Fukamachi et al. (2018).

The C-T recorder measured water conductivity and temperature at an interval of $10 \mathrm{~min}$ and with an accuracy of $\pm 0.3 \mathrm{mS} / \mathrm{m}$ and $\pm 2 \mathrm{mK}$, respectively. Salinity and potential temperature were calculated from United Nations Educational, Scientific and Cultural Organization algorithm (Fofonoff \& Millard, 1983) with an accuracy of $\pm 4 \times 10^{-3}$ and $\pm 3 \mathrm{mK}$, using the conductivity, temperature, and water pressure. Water pressure was measured by the T-P recorder, described below.

The turbidity sensor measured turbidity and chlorophyll- $a$ concentration at an interval of $1 \mathrm{~h}$. The turbidity was obtained in FTU (Formazin Turbidity Unit), which is the optical backscatter strength at near-infrared wavelength of $880 \mathrm{~nm}$ calibrated with a formazin solution. Although this is not an actual physical measurement of suspended matter, turbidity increases with suspended sediment concentration, SSC. However, turbidity also depends on the particle size distribution and type of resuspended sediment so that it cannot be converted to SSC without a calibration. As we were not able to obtain water samples for the calibration during episodes of high turbidity, we used turbidity expressed in FTU.

The ADCP measured the vertical profile of the current speed and acoustic backscatter strength at an interval of $15 \mathrm{~min}$. The ADCP cell length was set to $2 \mathrm{~m}$. The central depth of the deepest bin (bin 1) was $33 \mathrm{~m}(12 \mathrm{~m}$ above the bottom). The dynamic range and accuracy range of the echo intensity were \pm 1.5 and $80 \mathrm{~dB}$, respectively. The accuracy of the current speed was less than $1 \mathrm{~cm} / \mathrm{s}$. The acoustic frequency of the emitted ping was $307 \mathrm{kHz}$ corresponding to $5 \mathrm{~mm}$ in wavelength.

The T-P recorder measured the water temperature and pressure at an interval of $5 \mathrm{~min}$. The accuracies of those were $\pm 2 \mathrm{mK}$ and $\pm 1 \times 10^{7} \mathrm{~Pa}(0.1$ dbar or $0.1 \mathrm{~m}$ in depth), respectively. The pressure was recorded as the gauge pressure. It was converted to the water pressure using linearly interpolated hourly atmospheric pressure data (section 2.5).

\subsection{Acoustic Backscatter Strength}

The ADCP emits and receives acoustic pings with the same transducer. The acoustic pressure of the received ping is amplified and converted to an eight-bit digitized electric voltage amplitude in counts, called the echo amplitude. Because the echo amplitude is determined by the distance-dependent transmission loss and battery power, it cannot be compared between different bins and times. To correct for these effects, this study analyzes the volume backscatter strength, $S V$, in dB, which is the target strength per unit volume. $S V$ is calculated from the sonar equation (Deines, 1999) as follows:

$$
S V=k_{c}\left(E-E_{r}\right)+2 \alpha R+\psi 20 \log _{10} R+10 \log _{10} \frac{T_{x}}{L W_{t}}+C,
$$

where $k_{c}=0.45$ (dB/counts) is the conversion coefficient, $E$ is the echo amplitude (counts), $E_{r}$ is the received noise (counts), $\alpha$ is the attenuation coefficient $(\mathrm{dB} / \mathrm{m}), R$ is the range between the target and transducer $(\mathrm{m})$, $\psi$ is a transducer near-field correction, $T_{x}$ is the transducer temperature $(\mathrm{K}), L$ is the pulse length $(\mathrm{m}), W_{t}$ is the transmit power $(\mathrm{W})$, and $C=-143.5(\mathrm{~dB})$ is a constant. $R$ for bin $i(i=1,2,3, \ldots$ : central depth, $z,=33,31$, $29 \mathrm{~m}, \ldots)$ is calculated as $R=4.23+2.0(i-1) . E_{r}$ is derived from the echo amplitude before the deployment, and it was 42 counts. $L$ was set to $2.44 \mathrm{~m}$. The transducer temperature, $T_{x}$, was obtained from the T-P recorder, positioned at roughly the same depth as the transducer. $W_{t}$ was recorded by the instrument for every measurement. $\alpha$ is determined from the sum of the terms of the acoustic absorption by seawater and 
scattering and/or absorption by suspended matter. As in previous studies (e.g., Hoitink, 2004), the latter effect was ignored and $\alpha$ is assumed to be $0.069 \mathrm{~dB} / \mathrm{m}$ (Deines, 1999). Calculation of $\psi$ follows Downing et al. (1995) as

$$
\psi=\frac{1+1.35 \xi+(2.5 \xi)^{3.2}}{1.35 \xi+(2.5 \xi)^{3.2}}
$$

where

$$
\xi=\frac{R \lambda}{\pi a_{t}^{2}}
$$

where $\lambda(=5.0 \mathrm{~mm})$ is the wavelength and $a_{t}(=46 \mathrm{~mm})$ is the transducer radius.

\subsection{Supercooling}

Supercooling occurs when the water temperature drops the freezing point (in situ supercooling). The freezing point, $T_{f}$, is estimated from the UNESCO algorithm (Fofonoff \& Millard, 1983) using the salinity, $S$, and water pressure, $P_{w},(\mathrm{~Pa})$ as

$$
T_{f}\left(S, P_{w}\right)=a_{1} S+a_{2} S^{3 / 2}+a_{3} S^{2}+b P_{w},
$$

where $a_{1}=-0.0575\left({ }^{\circ} \mathrm{C}\right), a_{2}=1.710532 \times 10^{-3}\left({ }^{\circ} \mathrm{C}\right), a_{3}=-2.254996 \times 10^{-4}\left({ }^{\circ} \mathrm{C}\right)$, and $b=-7.53 \times 10^{-8}\left({ }^{\circ} \mathrm{C} /\right.$ Pa). $T_{f}$ derived from equation (4) has an error of at least $\pm 2 \mathrm{mK}$.

According to equation (4), the freezing point decreases with depth $(\sim 7.5 \mathrm{mK}$ per $10 \mathrm{~m})$. Potential supercooling is attained when the potential temperature is below the freezing point at the surface estimated as $T_{f}(S, 0)$. Potentially supercooled water becomes supercooled if it is raised adiabatically to the surface.

This study assesses in situ and potential supercooling at the depth of the C-T recorder $(34 \mathrm{~m})$. The water pressure of the instrument depth was estimated using the pressure measured by the T-P recorder and tilt of the ADCP. We assume that it can be estimated with an error on the order of $0.1 \mathrm{~m}$. Considering the accuracy of the water temperature, potential temperature, salinity, water pressure, and equation (4), $T_{f}$ can be estimated with an error of $\pm 6 \mathrm{mK}$.

\subsection{Sea Ice Radar}

Imagery of an X-band marine radar deployed near the coast at Utqiagivik was used to assess the ice conditions in the vicinity of the mooring site. The radar (Furuno FR-7112 $10 \mathrm{kHz}$, X band) is situated $22.5 \mathrm{~m}$ above sea level at $71.269^{\circ} \mathrm{N}, 156.788^{\circ} \mathrm{W}$, which is $5.3 \mathrm{~km}$ away from the mooring (Figure $1 \mathrm{~b}$ ). The mooring site was located within the 11-km effective operational range of the radar. Radar backscatter from sea ice pressure ridges, edges of ice floes and rough ice, and water surfaces is strong, whereas backscatter from flat ice surfaces and calm open water is weak (Mahoney, Eicken, \& Shapiro, 2007). Radar imagery was acquired every 5 min and archived by the Geophysical Institute, University of Alaska Fairbanks (http://feeder.gina.alaska. $\mathrm{edu} /$ ). The details of the coastal radar system and data processing are described in Jones et al. (2016).

\subsection{Meteorological Data}

This study used wind speed and direction and sea level pressure measured at Will Rogers Memorial Airport in Utqiagivik $\left(71.286^{\circ} \mathrm{N}, 156.766^{\circ} \mathrm{W}\right.$; Figure $\left.1 \mathrm{~b}\right)$. The temporal resolution of these data is $1 \mathrm{~h}$. The airport is located $6.4 \mathrm{~km}$ from the mooring site.

The 2-m air temperature was derived from the European Centre for Medium-Range Weather Forecasts Interim Re-Analysis (ERA-Interim) data. The spatial and temporal resolutions are $0.75^{\circ} \times 0.75^{\circ}$ and $6 \mathrm{~h}$, respectively. The data at the grid point $\left(71.25^{\circ} \mathrm{N}, 156.75^{\circ}\right)$ closest to the mooring site at a distance of $4 \mathrm{~km}$ were used. 


\section{Results}

\subsection{Ice Conditions at the Surface}

Drawing on radar imagery, ice conditions in the vicinity of mooring site were manually classified into three categories: (1) Ice cover: Strong radar backscatter with features of deformed ice or ice floe indicates the presence of ice floes or landfast ice (Figure 2a). We do not distinguish between ice types (drift, pack, or landfast ice) or floe sizes for the ice cover category. (2) Open water: Weak radar backscatter, distributed widely around the mooring site lacking backscatter features indicative of ice floe (nilas) edges, suggests open water (Figure 2b). (3) Frazil ice: Strong radar backscatter with streaks parallel to the wind direction suggests rough open water and frazil ice (Figure 2c).

Figure 3a shows the time series of ice conditions based on the above three categories for the period from 25 December 2014 to 23 January 2015. Episodic open water events, often associated with frazil ice at the surface, continued over 2-4 days around the mooring site. The IPS data (Figure 3b) show results consistent with open water or newly formed ice during these periods. During 3-5 and 11 January, the radar detected ice floes around the mooring site, while the IPS indicated that this was thin ice with $h_{i} \leq 0.2 \mathrm{~m}$. During 6-7 January, the IPS data showed short-term fluctuations between open water, thin ice, and thick ice (Figure 3b). The radar imagery showed that ice floes passed over the mooring site during this time period (not shown).

Figure $3 \mathrm{c}$ shows the time series of wind speed and direction. Continuous open water and thin ice periods described above correspond to periods when winds were directed offshore. This is confirmed by radar imagery showing creation of open water due to offshore ice movement (not shown). Thus, for such open water and thin ice periods, a coastal polynya or flaw lead was formed at the mooring site associated with winds toward the offshore. According to the radar imagery and IPS, the polynya periods were identified as follows: midnight on 28 December to morning on 29 December, afternoon on 30 December to night on 5 January, and midnight on 7 January to midnight on 23 January.

During periods of frazil ice formation (sky blue in Figure 3a), the wind speed mostly exceeded $\sim 10 \mathrm{~m} / \mathrm{s}$ directed to the offshore (Figure 3c), and wind rows of frazil ice were detected through higher radar backscatter.

\subsection{Underwater Frazil Ice and Resuspended Sediment}

Figure $3 \mathrm{~d}$ shows time series of the vertical profile of the volume backscatter strength, $S V$, (color) from the ADCP and ice thickness, $h_{i}$, (black shade) from the IPS. $S V$ at bins 16 and 17 (0-2 and 2-4 m) always showed quite high values because of backscatter by the ocean surface or ice bottom. Bins 1 and 2 (32-34 and 30-32 m) also showed higher $S V$ than other bins. This is due to backscatter by the instruments or buoys. These acoustic backscatter data were not used in this study. During the polynya periods on 28-29 and 30-31 December and 4-5 and 8-15 January, the acoustic signals with strong $S V$, which was enhanced toward the surface, were detected from the surface down to 10-30 m. During these periods except on 28-29 December, potential supercooling of 20-35 mK occurred at $34 \mathrm{~m}$ (Figure 3e). In addition, in situ supercooling of up to $10 \mathrm{mK}$ occurred on 10 and 12 January (Figure $3 \mathrm{e}$ ). The magnitude of observed in situ and potential supercooling was larger than the instrumental uncertainty ( 6 mK). During 28-29 and 30-31 December, the radar imagery indicated the presence of frazil ice near the surface (Figure 3a). In particular, during the night of 30 December to the morning of 31 December, when wind speed reached $17 \mathrm{~m} / \mathrm{s}$, the highest speed over the winter (Figure 3c), very strong acoustic backscatter signals with $S V$ exceeding $-70 \mathrm{~dB}$ were detected from the surface down to 25- to 30-m water depth (Figure 3d). The combination of these findings strongly suggests that such surface-intensified acoustic signals during polynya periods were caused by frazil ice suspended in the water column. The acoustic signal of frazil ice tends to be stronger for higher wind speed and/or lower air temperatures (Figure 3c). Such atmospheric conditions cause strong wind stirring and convection.

Air bubbles may be another possible source of strong upper ocean acoustic signals. During summer and fall in the absence of ice production, however, no such signals were detected (not shown). Therefore, bubbles can be excluded as major acoustic target and potential source of upper ocean backscatter signals. Zooplankton is another possible acoustic target. In general, such organisms would show diurnal vertical migration even in polar winter (Petrusevich et al., 2016) and be present independent of surface temperature, 


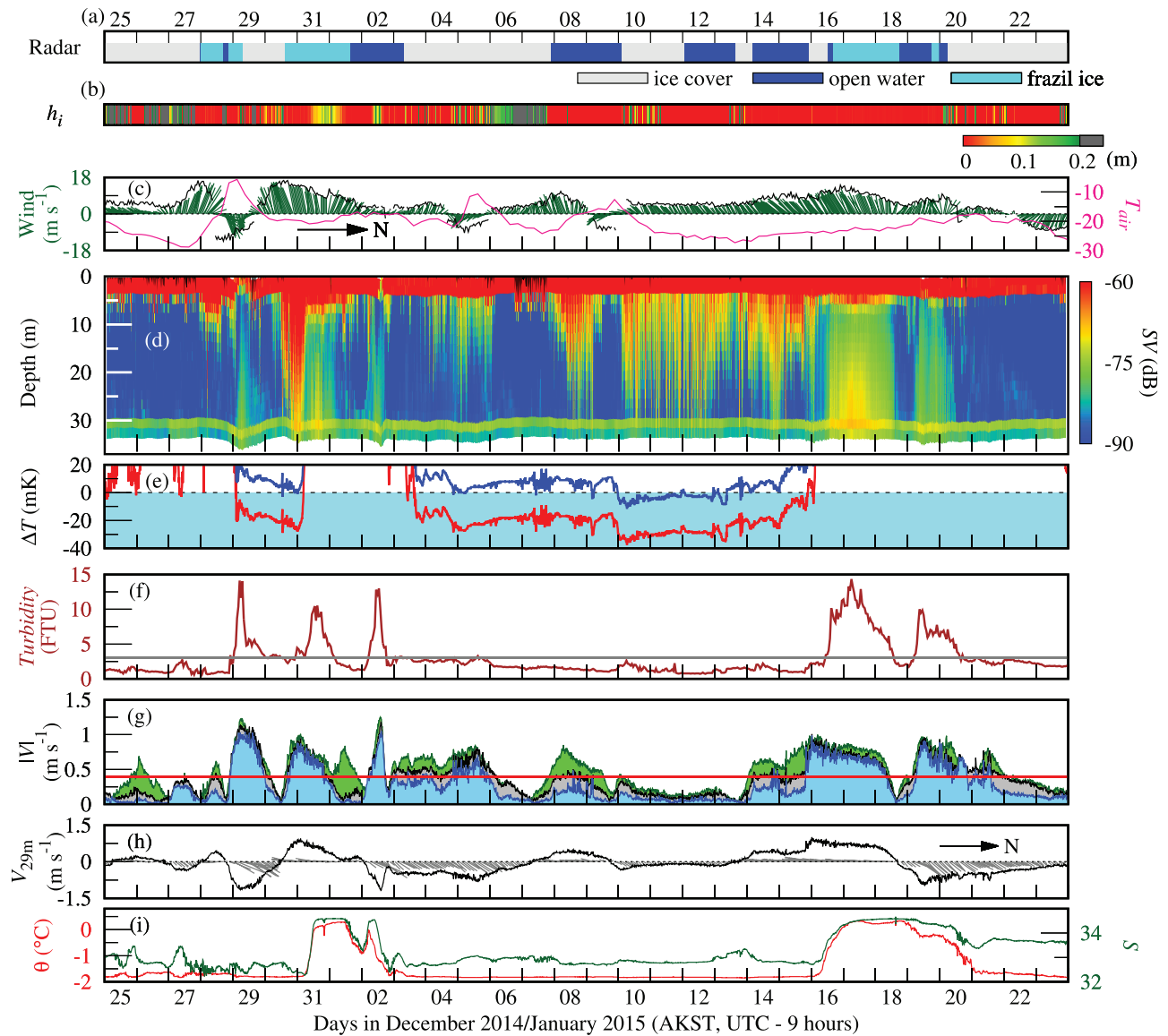

Figure 3. Time series of the sea ice radar, mooring, and meteorological data for the period from 25 December 2014 to 23 January 2015. Time is expressed as a local time (AKST, UTC - 9 h). (a) Ice conditions in the vicinity of the mooring site based on radar imagery. (b) Ice thickness, $h_{i}$, derived from the IPS data. Dark gray denotes thick ice $\left(h_{i}>0.2 \mathrm{~m}\right)$. (c) Stick plot of the wind velocity (green) and air temperature at $2 \mathrm{~m}$ (pink). Easterly wind is up, and westerly wind is down. The black curve shows the wind speed. Winds from easterly sectors are shown as positive, and winds from westerly as negative. (d) The vertical profile of the volume backscatter strength, $S V$, obtained from the ADCP (color) and ice draft derived from the IPS (black shade near the top). $S V$ at 0-4 $\mathrm{m}$ was always higher than that at other layers because of the backscatter from the surface or ice bottom. (e) The water temperature at 34-m depth relative to the in situ freezing point (blue) and the potential temperature relative to the freezing point at the surface (red). The light blue shade indicates supercooling. (f) Turbidity at $35 \mathrm{~m}$. The gray line denotes a turbidity of 3.0 FTU. (g) The absolute values of the current speeds at 14-16 (green), 28-30 (gray), and 32-34 m (blue). The red line denotes the speed of $0.37 \mathrm{~m} / \mathrm{s}$. (h) The stick plot of the current at 28-30 m (gray). The black curve shows the southwestward (up-canyon) component of the current. (i) The potential temperature (red) and salinity (green) at $34 \mathrm{~m}$.

wind, or current conditions. However, our ADCP data did not show such diurnal cycle, and hence, zooplankton is also excluded as a source of high-backscatter signals.

On the other hand, during 28 and 31 December, 16-18, and 19-20 January, acoustic signals with strong $S V$ were detected from the deepest bin (bin 1: 32-34 m) up to the near-surface layers, with bottom intensification (Figure 3d). Bottom-intensified $S V$ suggests that the source of the signals is attributed to the seafloor. The acoustic characteristics of these signals are different from those expected from air bubbles and zooplankton. In addition, turbidity at $35 \mathrm{~m}$ increased ( $>\sim 5.0 \mathrm{FTU}$; Figure $3 \mathrm{f}$ ) at times of bottom-intensified acoustic signals. The fact that chlorophyll- $a$ concentrations obtained by the turbidity sensor were zero throughout the winter (not shown) indicates an absence of phytoplankton at the depth of the sensor. Thus, the scatterers associated with these acoustic signals are probably resuspended sediments. Resuspended sediment was detected during periods of strong currents regardless of their direction (Figures $3 \mathrm{~d}, 3 \mathrm{~g}$, and $3 \mathrm{~h}$ ). Thus, we can consider that detected sedimentary particles mainly originated from the seafloor around the mooring 
site and not from advection. Upward sediment dispersion and transport will be discussed in sections 4.1 and 4.2 .

\subsection{Occurrence of Suspension Freezing}

As described in section 3.2, during the afternoon of 30 December through the early morning of 31 December, frazil ice characterized by surface-intensified $S V$ appeared from the surface down to at least bin 3 (28-30 m) (Figure 3d). At the same time, $S V$ in bins 1 and 2 (30-32 and 32-34 m, respectively) was clearly enhanced as well, indicating the presence of frazil ice. During this period, optical turbidity at $35 \mathrm{~m}$ was $3.0-4.5$ FTU (Figure 3f), which was larger than that of the typical background signal ( $<2.0$ FTU). This finding suggests that the sedimentary particles were also suspended at around $35 \mathrm{~m}$ in depth. In such a case, frazil ice can come into contact with sedimentary particles in the water column, that is, suspension freezing may occur.

When massive upward sediment transport occurred (29 and 31 December, 2, 16-18, and 19-20 January; Figures 3d and 3f), underwater frazil ice did not appear at depth (Figure 3d). During these periods except on 29 December, significant increases in water temperature and salinity occurred (Figure 3i). This is due to upwelling of the warm and saline Atlantic water associated with southwestward current (up-canyon flow) through Barrow canyon (Figure 3h). In such cases, underwater ice production was likely suppressed (Hirano et al., 2016; Ito et al., 2015). This finding further supports our interpretation that the surface-intensified signals were caused by frazil ice and not by air bubbles. At such times, the radar imagery also provides evidence of the presence of frazil ice (Figure 3a). During these events, wind speed mostly exceeded $10 \mathrm{~m} / \mathrm{s}$ (Figure 3c), implying intense atmospheric cooling at the surface. On 31 December and 16-18 January, surfaceintensified acoustic signals, which were different from those of sedimentary particles, were detected in bins 15-13 ( $z=5-9 \mathrm{~m})$ just below the high backscatter layers near the surface in bins 17 and 16 (Figure 3d). These signals are considered to be backscatter from frazil ice. Since the bottom sediment was transported to the near-surface layers in such events, suspension freezing can occur at shallow depths.

\section{Discussion}

\subsection{Estimating Sediment Particle Suspension Depth}

In this subsection, we assess whether sedimentary particles were suspended in the water column and how far these were transported upward, based on $S V$ from the ADCP and turbidity from the turbidity sensor (acoustic and optical instruments). On 30 December, 8, 10, 11, 12, and 14 January, frazil ice was detected by the ADCP down to bin $1(32-33 \mathrm{~m})$, but optical turbidity obtained by the turbidity sensor was not enhanced (Figures 3d and 3f). During these periods, current speeds remained at low values of $0.1-0.2 \mathrm{~m} / \mathrm{s}$ (Figure 3g), which provided the condition of no sediment resuspension from the seafloor. Thus, optical turbidity is considered to be enhanced only by resuspended sediment, allowing the detection of resuspended sediment by the turbidity sensor at an instrument depth of $35 \mathrm{~m}$. The period of highest $S V$ (30-31 December) cannot be used to assess the effect of frazil ice on optical turbidity measurements because of the co-occurrence of frazil ice and sediment particles as a result of high current speeds $(0.5-1.0 \mathrm{~m} / \mathrm{s}$, Figure $3 \mathrm{~g}$ ). Figures $4 \mathrm{~b}$ and $4 \mathrm{c}$ show time series of the vertical profile of $S V$ and turbidity over winter (December-April). The former (Figure 4b) indicates several events of sediment transport up to near-surface layers. During these periods, turbidity was larger than 5.0 FTU (Figure 4c), as in the cases described in section 3.2. On the other hand, on 20 and 23 December and 19-21 April, for example, turbidity was larger than the background signal of $<2.0$ FTU (Figure 4c), whereas the ADCP did not detect any acoustic signals of sediment transported into the upper water column (Figure $4 \mathrm{~b}$ ). For these periods, bottom sediment was likely transported up to around the depth of turbidity sensor, which was $10 \mathrm{~m}$ above the bottom, but not to shallower depths. Here we assume conservatively that bottom sediment is transported up to at least the depth of the turbidity sensor ( $35 \mathrm{~m}, 10 \mathrm{~m}$ above the bottom) whenever turbidity $\geq 3.0$ FTU (blue line in Figure 4c). Turbidity data which satisfied this condition account for $13 \%$ of the entire time period over the winter.

For depths shallower than the turbidity sensor, we use $S V$ for detection of resuspended sediment. The deepest ADCP bin that can stably provide the valid backscatter data is bin 3, because $S V$ in bins 1 and 2 was affected by the plastic buoys and other instruments (Figure 3d and section 3.2). As described in section 3.2 , $S V$ was enhanced by not only sedimentary particles but also other targets such as frazil ice. For simplicity, in this study we assume that the acoustic target in ADCP bins is either resuspended sediment of frazil ice 


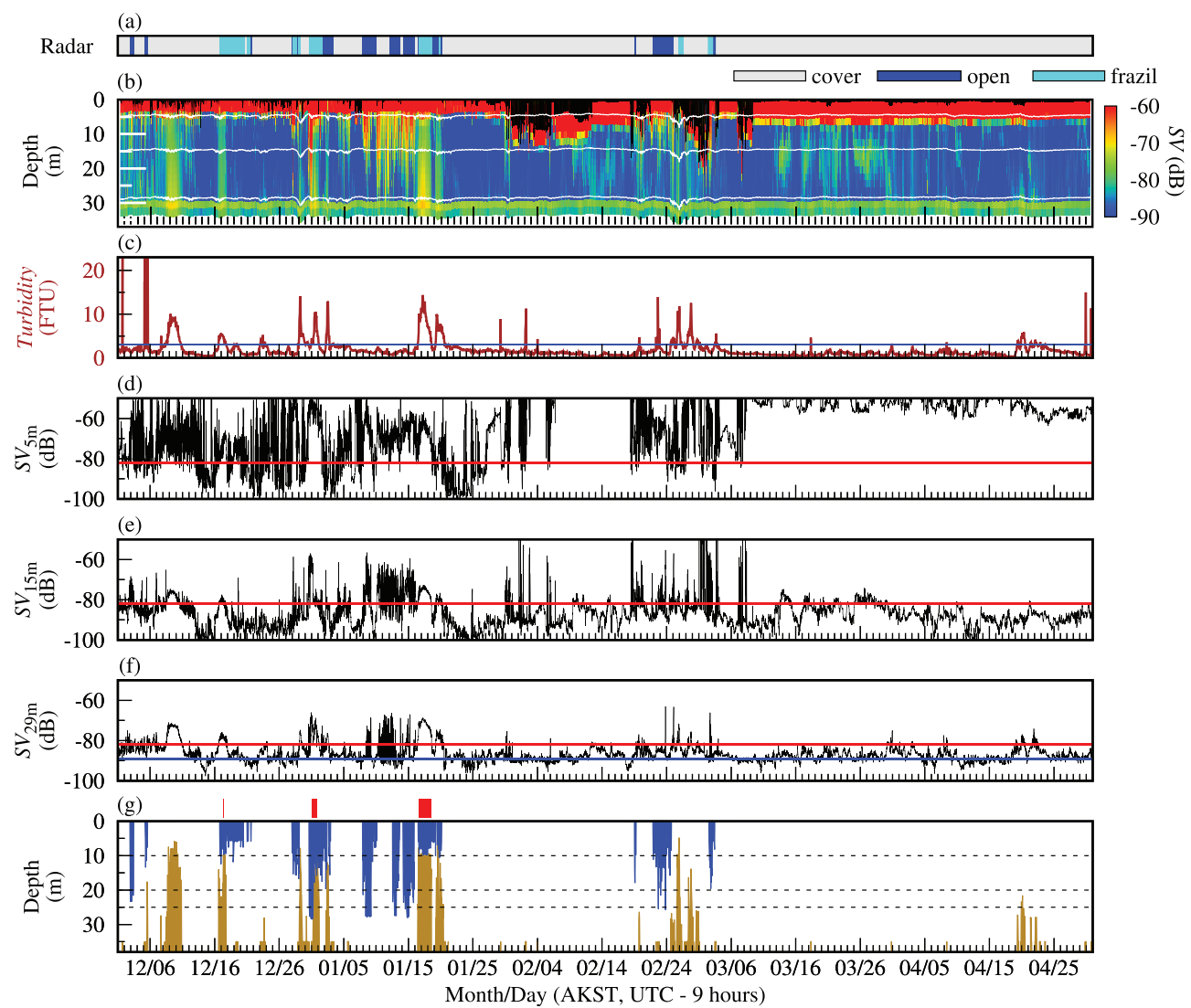

Figure 4. Mooring and sea ice radar time series for the period from 1 December 2014 to 30 April 2015. (a) Ice conditions around the mooring site derived from radar imagery. (b) Vertical profile of $S V$ (color) and ice draft (black shade near the top). White lines show the depths of ADCP bins 3, 10, and 15. (c) Turbidity at $35 \mathrm{~m}$. The blue line denotes turbidity of 3.0 FTU. (d-f) $S V$ at bin 15 (4-6 m), 10 (14-16 m), and 3 (28-30 m), respectively. Red lines denote $S V$ of $-82 \mathrm{~dB}$. Blue line in Figure $4 \mathrm{f}$ denotes $S V$ of $-89 \mathrm{~dB}$. (g) The deepest and shallowest depths at which frazil ice and sedimentary particles suspended, $Z_{f}$ and $Z_{S}$ (blue and khaki shade), respectively. Dashed lines denote 10, 20, and $25 \mathrm{~m}$ in depth. Red bars above this panel show timing of favorable condition for suspension freezing.

solely, but not both. According to Figures $4 \mathrm{~b}$ and $4 \mathrm{f}$, when the ADCP detected some underwater targets such as sediment or frazil ice, $S V$ was larger than at least $-89 \mathrm{~dB}$ (blue line in Figure $4 \mathrm{f}$ ). Hence, we conservatively regard $S V$ of $-89 \mathrm{~dB}$ as the background value. Considering the fact that the source of resuspended sediment is the seabed around the mooring site, when sedimentary particles were suspended within the observable

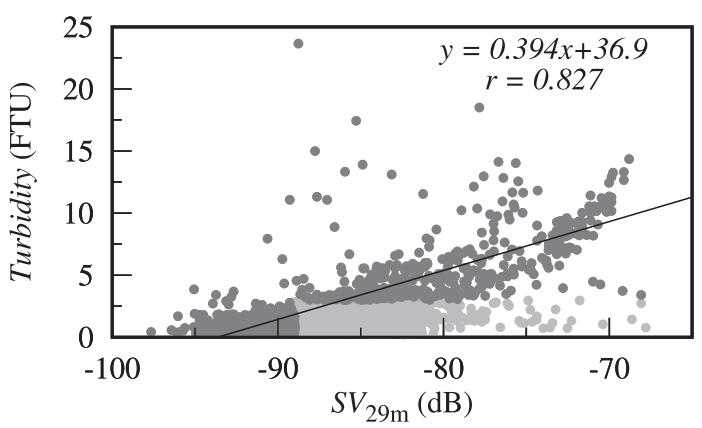

Figure 5. Scatterplot of $S V$ in bin $3(28-30 \mathrm{~m})$ and turbidity at $35 \mathrm{~m}$ during winter. The black line denotes the linear regression line for the data shown by dark gray dots, which exclude those with turbidity $<3.0$ FTU and $S V \geq 89 \mathrm{~dB}$ (light gray). range of the ADCP (depth $\leq 30 \mathrm{~m}$ ), these should have been suspended at the depth of the turbidity sensor $(35 \mathrm{~m})$. Thus, for the case of turbidity $<3.0$ FTU and $S V \geq-89 \mathrm{~dB}$, the major acoustic target should not be resuspended sediment. Excluding these data, the scatterplots of turbidity and $S V$ at bin 3 (Figure 5) indicates positive strong correlation $(r=0.827)$, and its linear regression line is obtained as

$$
\text { Turbidity }=0.394 \times S V+36.9 \text {. }
$$

Assuming that the transmit loss is properly corrected by equations (1)-(3) and that most of the acoustic target is resuspended sediment, turbidity for any ADCP bins can be estimated from this equation. The presence of resuspended sediment was indicated by this estimated turbidity exceeding 3.0 FTU. It is noted that equation (5) may somewhat overestimate turbidity because the central depth of bin 3 was $6 \mathrm{~m}$ shallower than the turbidity sensor depth. 


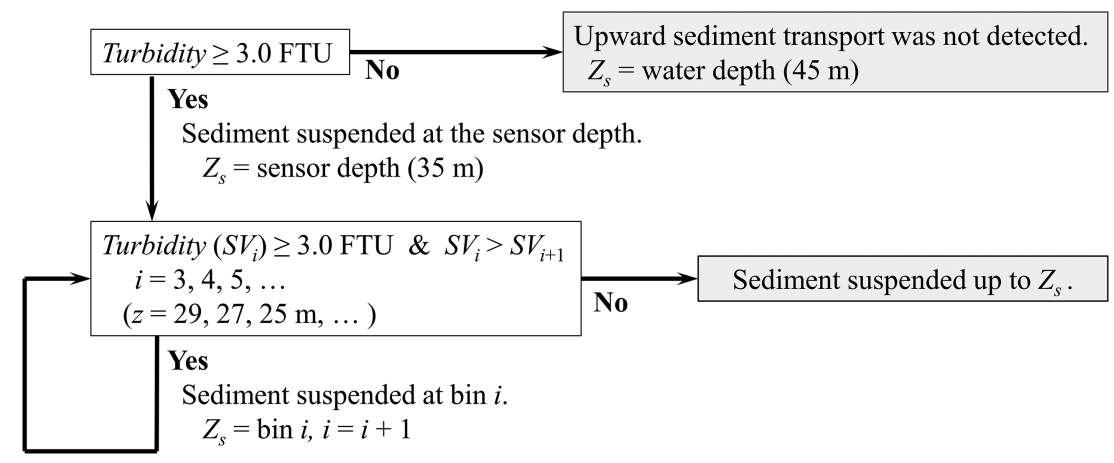

Figure 6. The algorithm to estimate the shallowest suspension depth of sedimentary particles, $Z_{s}$. Turbidty $\left(S V_{i}\right)$ denotes the turbidity estimated from the regression line between turbidity and $S V$ of equation (5), using $S V$ at bin $i(i=3,4,5, \ldots ; z$ $=29,27,25 \mathrm{~m}, \ldots)$.

Finally, it should be mentioned that even if both turbidity measured by the turbidity sensor and estimated from $S V$ were larger than $3.0 \mathrm{FTU}$, the acoustic target was not always resuspended sediment. Thus, the co-occurrence of resuspended sediment and frazil ice enhances turbidity and $S V$ individually. Hence, for the range of the ADCP data, acoustic signals of resuspended sediment should be discriminated from those of frazil ice by using $S V$ data. $S V$ of frazil ice tended to increase toward the surface (section 3.2), while that of sediment transported from the bottom should increase toward the bottom.

Based on this analysis, we can assess whether sedimentary particles are suspended at a certain depth by evaluating the following two conditions. (I) For the case that turbidity obtained by the turbidity sensor is larger than 3.0 FTU, we assume that sedimentary particles are suspended at least up to the depth of the sensor (35 m). (II) For the case that turbidity estimated from $S V$ in bin $i$ is larger than 3.0 FTU and that $S V$ in bin $i$ is larger than $S V$ in bin $i+1$, we assume that sedimentary particles are suspended in bin $i$. This condition is interactively evaluated from $i=3$ to $i=14$ (near surface). If condition I is not satisfied, we assume that sediment resuspension did not occur. By evaluating condition I and iterative evaluation of condition II, we can estimate the shallowest suspension depth of sedimentary particles, $Z_{s}$. Figure 6 is a flow chart illustrating this method to estimate $Z_{S}$.

Figure $4 \mathrm{~g}$ shows time series of $Z_{s}$ (khaki shade). Variability in $Z_{s}$ corresponds well with that of visual estimates of bottom-intensified signals in the vertical profile of $S V$ (Figure $4 \mathrm{~b}$ ). Sediment particles could reach up to near surface during massive resuspension events. As indicated by the strong signal traced in Figure $4 \mathrm{~b}$, these particles were likely transported from the bottom to the near-surface layer within several hours $(\sim 5 \mathrm{~h})$. In some cases, in layers shallower than $Z_{s}, S V$ was intensified toward the surface (Figure $4 \mathrm{~b}$ ). This implies that the major acoustic target was not resuspended sediment at these shallower depths. However, this finding does not fully preclude the presence of resuspended sediment in these layers. Frazil ice may account for such high backscatter near the surface and may have interacted with and entrained responded sediment in such shallow layers. This possibility will be discussed in section 4.5. $Z_{S}$ shown in Figure $4 \mathrm{~g}$ also indicates that sedimentary particles were transported to the depth of the turbidity sensor ( $35 \mathrm{~m}: 10 \mathrm{~m}$ above the bottom) much more frequently than into the nearsurface layers.

\subsection{Triggering Upward Sediment Transport}

As described in section 3.2, upward sediment dispersion was likely induced by strong currents. Variation in turbidity (Figure 3f) corresponded well with those in current speed, in particular near the bottom (Figure 3g). The correlation between turbidity and current speed in winter (December-April) increases with depth (black curve in Figure 7a). However, the vertical range of saltation driven by the horizontal currents is within the thickness of bottom boundary layer. The ADCP showed that the current was generally uniform vertically over the depth from bin $1(32-34 \mathrm{~m})$ to near surface (Figure $3 \mathrm{~g}$ ). This fact implies that the bottom boundary layer was thinner than the distance between the bottom and bin $1(\sim 9 \mathrm{~m})$, and thus, an additional mechanism is needed to transport dispersed sedimentary particles up to the ocean 

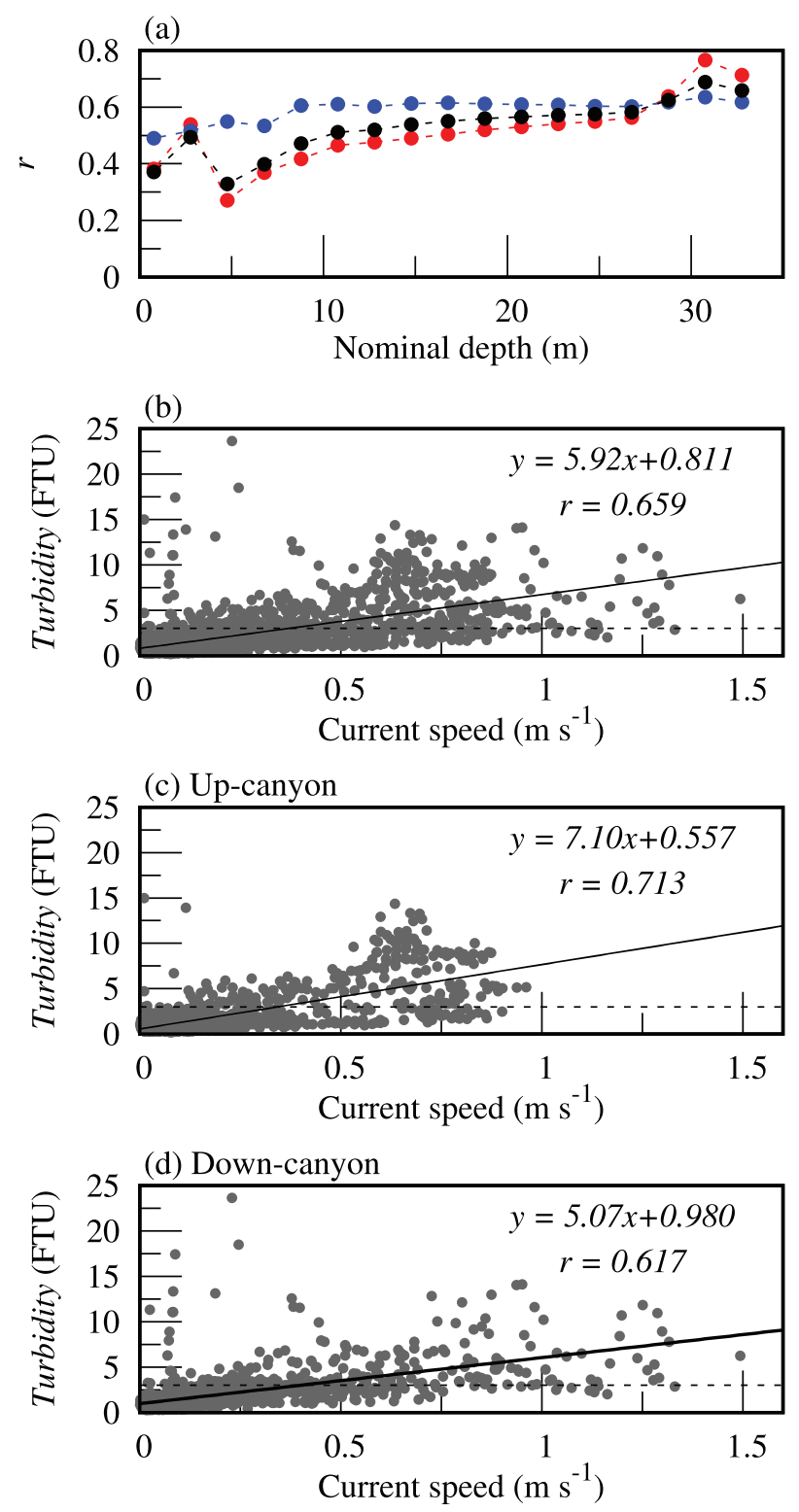

Figure 7. (a) Vertical profiles of the correlation coefficient between the turbidity and the current speed (black) over winter. Blue and red circles indicate correlation between turbidity and current speed for down- and upcanyon flows (positive and negative northeastward components), respectively. (b) The scatterplot between turbidity and current in bin 1 (32-34 m). The solid line denotes the regression line. The dashed line denotes the turbidity of 3.0 FTU. (c and d) Similar to Figure 7b except for the case of up- and down-canyon flows, respectively. surface. In shelf regions, convection induced by strong atmospheric cooling in a polynya can penetrate down to the seafloor. In addition, strong winds during polynya episodes (Figure 3c) significantly stir the water column from the surface. Such convection and wind stirring promote upward sediment transport.

Figure $7 \mathrm{~b}$ shows the scatterplot of turbidity and the current speed in bin 1 (32-34 m), with $r=0.659$. The linear regression line for the plot is as follows:

$$
\text { Turbidity }=5.92 \times\left|V_{33 \mathrm{~m}}\right|+0.811 \text {, }
$$

where $\left|V_{33 \mathrm{~m}}\right|$ is the absolute value of the current speed at bin 1 . According to the discussion in section 4.1, sediment resuspension occurs for a turbidity of $\geq 3.0$ FTU, which corresponds to a current speed of $\geq 0.37 \mathrm{~m} / \mathrm{s}$ in bin 1 based on the regression line of equation (6). Although this threshold value should be determined by using current data closer to the bottom, timing of the current speed at bin $1 \geq 0.37 \mathrm{~m} / \mathrm{s}$ (red line in Figure $3 \mathrm{~g}$ ) coincides well with those of sediment resuspension estimated from the turbidity and the vertical profile of $S V$ (Figures $3 \mathrm{~d}$ and $3 \mathrm{f}$ ).

The current direction in the vicinity of the mooring site is typically parallel to Barrow Canyon, southwestward and northeastward (upand down-canyon) flows (Figure 3h, Hirano et al., 2016). Here we distinguish between up- and down-canyon flows as negative and positive northeastward components of the current. The current direction is not an essential factor of upward sediment dispersion, as mentioned in section 3.2. Thus, the vertical profile of the correlation coefficient between the turbidity and the current speed for the case of up- and down-canyon flows are almost the same for greater depths (red and blue curves in Figure 7a). On the other hand, the up-canyon flow frequently accompanies the upwelling of Atlantic water from the deeper waters in the Canada Basin (Hirano et al., 2016, 2018). This potentially contributes to upward sediment transport. As described in section 3.2, sediment particles were transported into the near-surface layers during such upwelling events, identified by rapid increase in water temperature and salinity (Figures $3 \mathrm{~d}$ and $3 \mathrm{i}$ ). However, the role of upwelling in upward sediment transport is not clear because the current speed was also large during these periods (Figure $3 \mathrm{~g}$ ). In order to assess this effect, the regression relation between turbidity obtained by the turbidity sensor and the current speed in bin 1 for the cases of down- and up-canyon flows is calculated separately (Figures $7 \mathrm{c}$ and $7 \mathrm{~d}$ ). The slope of the linear regression line for up-canyon flow of 7.10 is 1.4 times larger than that for down-canyon flow of 5.10. This fact suggests that more sediment was transported upward during the period of upcanyon flow than that of down-canyon flow. Upwelled Atlantic water can directly bring resuspended sediment into the near-surface layers. However, episodes of strong up-canyon flow corresponded to polynya episodes with strong winds (Figures 3a, 3c, and 3h). Under such conditions, strong wind stirring is promoted and it also can enhance upward transport of resuspended sediment.

\subsection{Suspended Sediment Concentration}

In this subsection, we estimate the size and concentration of resuspended sediment. According to Greenlaw (1979), $S V$ is related to the number of acoustic targets per unit volume, $N$, as follows: 


$$
S V \approx 10 \log _{10} \sigma_{\mathrm{bs}} N
$$

where $\sigma_{\mathrm{bs}}$ is the backscatter cross section. Assuming spherical targets with the radius of $a, \sigma_{\mathrm{bs}}$ is expressed as follows (Johnson, 1977):

$$
\sigma_{\mathrm{bs}}=\pi a^{4}\left[4\left(\frac{1-r_{\rho}\left(c_{t} / c_{\mathrm{sw}}\right)^{2}}{3 r_{\rho}\left(c_{t} / c_{\mathrm{sw}}\right)^{2}}+\frac{1-r_{\rho}}{1+2 r_{\rho}}\right)\right]\left[\frac{2(k a)^{4}}{2+3(k a)^{4}}\right]
$$

where $r_{\rho}$ is the specific gravity of target particles relative to seawater, $c_{t}$ and $c_{\mathrm{sw}}(=1,500 \mathrm{~m} / \mathrm{s})$ are the sound speed in target particles and seawater, respectively, and $k$ is the wave number of incident waves. The acoustic frequency of $307 \mathrm{kHz}$ for our ADCP corresponds to $k=1,286 \mathrm{~m}^{-1}$. In the following, we assume resuspended sediment is natural sand, that is, with a density, $\rho$, and $c_{t}$ of $2.65 \times 10^{3} \mathrm{~kg} / \mathrm{m}^{3}$ and $5700 \mathrm{~m} / \mathrm{s}$ (values of $\mathrm{SiO}_{2}$ ), respectively. The density of seawater is regarded as $1025 \mathrm{~kg} / \mathrm{m}^{3}$.

The particle size is estimated from the conditions under which the bottom current strength is sufficient to result in upward sediment dispersion. Specifically, the friction velocity, $u^{*}$, is larger than both of the incipient friction velocity, $u_{c}^{*}$, and the settling velocity of the particle, $w_{f}$. Based on the log-profile method, $u^{*}$ is represented as follows:

$$
\frac{u\left(z^{\prime}\right)}{u^{*}}=\frac{1}{\kappa} \ln \left(\frac{z^{\prime}}{z_{0}}\right),
$$

where $z^{\prime}$ is the distance from the bottom (water depth $-z$ ), $u\left(z^{\prime}\right)$ is the current speed at $z^{\prime}, \kappa=0.4$ is the von Karman coefficient, and $z_{0}$ is the roughness length. Here we set $z_{0}=3.0 \times 10^{-6} \mathrm{~m}$ under an assumption of a smooth ocean bed (Pope et al., 2006), although $z_{0}$ strongly depends on the bottom environment. $u_{c}^{*}$ is calculated following Iwagaki (1956) as a function of the diameter of sediment particle, $D(=2 a)$. $w_{f}$ is derived from Rubey's law (Rubey, 1933)

$$
w_{f}=\sqrt{\left(r_{\rho}-1\right) g D}\left(\sqrt{\frac{3}{2}+\frac{36 v^{2}}{\left(r_{\rho}-1\right) g D^{3}}}-\sqrt{\frac{36 v^{2}}{\left(r_{\rho}-1\right) g D^{3}}}\right)
$$

where $g$ is the gravitational acceleration and $v$ is the kinematic viscosity coefficient.

As shown in section 4.2, sediment dispersion occurs under conditions of $u$ in bin $1\left(z^{\prime}=12 \mathrm{~m}\right) \geq 0.37$ $\mathrm{m} / \mathrm{s}$. This value of $0.37 \mathrm{~m} / \mathrm{s}$ corresponds to $u^{*}=9.7 \times 10^{-3} \mathrm{~m} / \mathrm{s}$ from equation (9). Then, $u^{*}$ requires a sedimentary particle size with $D=40 \mu \mathrm{m}$ for $u^{*}>=u_{c}^{*}$. Finally, $w_{f}$ for $D=40 \mu \mathrm{m}$ is estimated to be $1.4 \times 10^{-3} \mathrm{~m} / \mathrm{s}$ from equation (10), under the condition of $u^{*}>w_{f}$. Our data suggest that sedimentary particles with a diameter of $\leq 40 \mu \mathrm{m}$ can be resuspended and dispersed typically. We note that current speeds in bin 1 were up to $\sim 1 \mathrm{~m} / \mathrm{s}$ during polynya episodes (Figure $3 \mathrm{~g}$ ), indicating potential resuspension of larger sediment particles.

As described in section 4.1, once sedimentary particles are dispersed from the bottom, they are transported toward the surface through wind stirring and winter convection. If the associated vertical velocity is less than $w_{f}$, the particles cannot be transported upward. Typical vertical velocities associated with the winter convection are on the order of $10^{-2}$ to $10^{-3} \mathrm{~m} / \mathrm{s}$ (Ito et al., 2017; Schott et al., 1993), which is comparable to $w_{f}$ of sediment particles with $D \leq 40 \mu \mathrm{m}\left(1.4 \times 10^{-3} \mathrm{~m} / \mathrm{s}\right)$. Conservatively, this indicates that sediment particles with $D \leq 20 \mu \mathrm{m}$, whose $w_{f}$ is smaller than $4.0 \times 10^{-4} \mathrm{~m} / \mathrm{s}$, can be transported upward. Sediment particles may settle faster than accounted for in calculations that assume solitary particles due to flocculation and/or pelletization. We ignored this effect in our analysis, possibly leading to an overestimate of the grain size of sediment that can be transported upward.

According to above discussion, the size of resuspended sediment is estimated to be smaller than $40 \mu \mathrm{m}$ or conservatively $20 \mu \mathrm{m}$. These particles are categorized as silt. This is consistent with the observation by Darby et al. (2011) reporting that the size of sediment inside sea ice in the Arctic Ocean is silt size. Thus, we infer that those resuspended sediment particles with $D<40$ or $20 \mu \mathrm{m}$ are incorporated into sea ice in the polynya. 


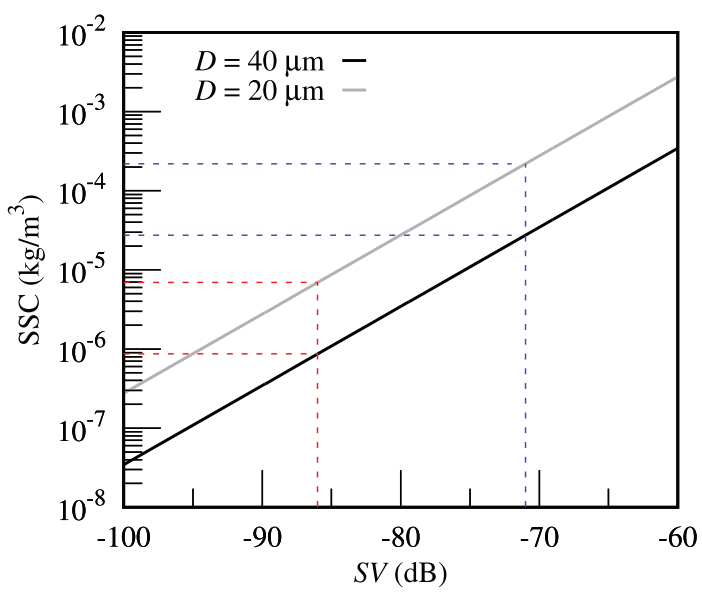

Figure 8. Suspended sediment concentration, SSC, estimated from $S V$ for sediment particles with 40 and $20 \mu \mathrm{m}$ in diameter (black and gray, respectively). Dashed lines denote SSC for $S V=-86$ (red) or -71 (blue) dB.
Here we can estimate the SSC from the size of resuspended sediment, $D$ (= $2 a$ ). The number of the particles per unit volume, $N$, is derived from equations (7) and (8). $N$ is converted to SSC through SSC $=N \rho(4 / 3) \pi a^{3}$. Figure 8 shows SSC for 40 and $20 \mu \mathrm{m}$ in diameter, $\mathrm{SSC}_{40}$ and $\mathrm{SSC}_{20}$, respectively, as functions of $S V$. $\mathrm{SSC}_{20}$ is 1 order larger than $\mathrm{SSC}_{40}$ for the same $S V$. As stated in section 4.1, the turbidity would be larger than 3.0 FTU when upward sediment dispersion and transport occurred. This turbidity corresponds to $S V \geq-86 \mathrm{~dB}$ based on the regression line of equation (5). Then, the value of $-86 \mathrm{~dB}$ can be regarded as the minimum value of $S V$ for resuspended sediment. On the other hand, during events of sediment resuspension, $S V$ reached $-71 \mathrm{~dB}$ in bin 1 on 17 January (Figures $4 \mathrm{~b}$ and $4 \mathrm{f}$ ). Thus, the range of $S V$ for resuspended sediment is $-71 \geq S V \geq$ $-86 \mathrm{~dB}$ (vertical dashed lines in Figure 8 ). This range is converted to that of SSC as $2.7 \times 10^{-5} \geq \mathrm{SSC}_{40} \geq 8.7 \times 10^{-7} \mathrm{~kg} / \mathrm{m}^{3}$ and $2.2 \times 10^{-4} \geq \mathrm{SSC}_{40} \geq$ $6.9 \times 10^{-6} \mathrm{~kg} / \mathrm{m}^{3}$ (horizontal dashed lines in Figure 8).

\subsection{Estimation of Suspension Depth of Frazil Ice}

Frazil ice was detected by the ADCP as a column of high acoustic backscatter signals with surface-intensified $S V$, as described in section 3.2 (Figure 3d). Frazil ice likely did not enhance optical turbidity, as shown in section 4.1. Considering these acoustic and optical characteristics, we determine whether frazil ice is suspended or not at each ADCP bin using the $S V$ data.

Bins $15(4-6 \mathrm{~m})$ and 3 (28-30 $\mathrm{m}$ ) are the shallowest and deepest bins that provided valid acoustic backscatter strength data in this study. Examining $S V$ at 4- to 6-, 14- to 16-, and 28- to 30-m depth (Figures 4d-4f), $S V$ of underwater frazil ice should be larger than at least $-82 \mathrm{~dB}$ (red lines in Figures $4 \mathrm{~d}-4 \mathrm{f}$ ). We regard this value as the minimum threshold of $S V$ for the presence of underwater frazil ice. The bottom of thick ice floes (black shade in Figure 4b) or resuspended sediment also could induce such strong backscatter. According to Figure $4 \mathrm{~b}$, when thick ice covered the mooring site, $S V \mathrm{~s}$ in bins of few meters below the ice bottom were clearly enhanced. This implies that ice floes somewhat affect backscatter data in these bins. To extract the backscatter signals of underwater frazil ice only, we have to exclude those of ice floes and resuspended sediment.

Backscatter signals affected by ice floes can be identified using a combination of ice conditions estimated from the radar imagery (Figure 4a) and ice draft derived from the IPS data (black shade in Figure 4b). When the radar imagery indicates ice floes near the mooring site (ice cover condition shown by light gray in Figure 4a), strong acoustic backscatter detected by the ADCP in shallow bins can be considered as originating from ice floes. Next, to identify the acoustic effects from ice floes difficult to detect in radar imagery, such as a flat undeformed ice, the draft data derived from the IPS measurement were used. Field measurement in an Arctic polynya (Smedsrud \& Skogseth, 2006) reported that grease ice can pile up to $1 \mathrm{~m}$ in thickness. The bottom of slushy grease ice layers can be detected by upward looking sonars as ice draft (Drucker et al., 2003). Considering these facts, during periods of ice draft $>1 \mathrm{~m}$, strong backscatter at shallow depths may be interpreted as that of ice floes even if the radar imagery indicates open or frazil cases. Small floes with draft $\leq 1 \mathrm{~m}$ that is not detected by the radar imagery are assumed not to affect the backscatter data at greater depth than bin 15 (4-6 m).

Next, we separate acoustic backscatter signals of underwater frazil ice from those of resuspended sediment. As described in section 4.1, $S V$ caused by resuspended sediment increases toward the bottom, whereas that by underwater frazil ice increases toward the surface. Hence, we assume that acoustic signals of underwater frazil ice are identified by monotonous vertical decrease in $S V$ from bin 15 toward deeper bins. This implicitly assumes that active frazil ice formation does not occur at some depth below the surface.

Based on this assessment, we can evaluate whether frazil ice is suspended or not at bin $i$ through the following two steps. (I) If the radar imagery indicates open water or frazil ice cases and the IPS data show ice draft $\leq 1 \mathrm{~m}$, we consider underwater frazil ice to be present (and go to the next step). (II) For the case of $S V$ in bin $i$ $\geq-82 \mathrm{~dB}$ and $S V$ in bin $i>S V$ in bin $i-1$, the major scatterer in bin $i$ is regarded as underwater frazil ice. This step is iterated from $i=15$ to $i=4$ as long as it is satisfied. On the other hand, if neither of Step I or Step 


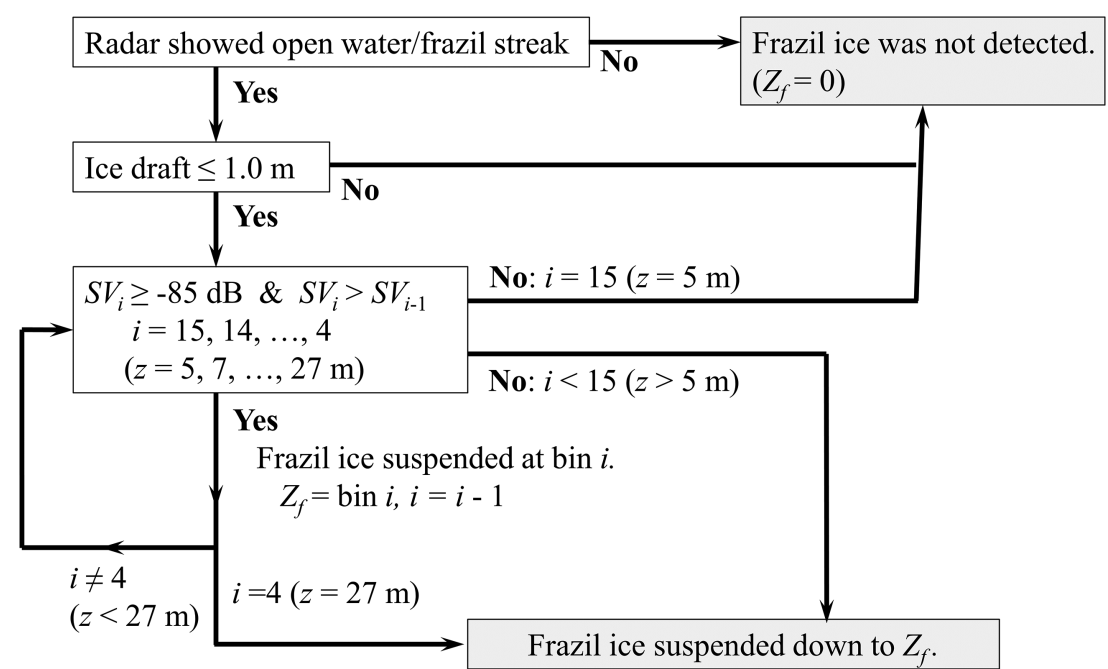

Figure 9. The algorithm to determine the deepest suspension depth of frazil ice, $Z_{f} . S V_{i}$ denotes $S V$ in bin $i(i=15,14$, $13, \ldots, 4)$

II for $i=15$ is satisfied, we conclude that no frazil ice has been detected throughout the water column. Through Step 1 and iteration of Step 2, we can determine the deepest suspension depth of frazil ice, $Z_{f}$. The algorithm to determine $Z_{f}$ is summarized as a flow chart in Figure 9.

Figure $4 \mathrm{~g}$ shows time series of $Z_{f}$ (blue shade). Variability of $Z_{f}$ is consistent with the visual estimation of underwater frazil ice from the vertical profile of $S V$ (Figure $4 \mathrm{~b}$ ). It is noted that $Z_{f}$ is limited to $28 \mathrm{~m}$ (bin 4) because the final iteration of Step 2 is $S V$ at bin $4>S V$ at bin 3. Figure $4 \mathrm{~g}$ demonstrates that frazil ice frequently appeared down to $20-25 \mathrm{~m}$ in depth (dashed lines in Figure $4 \mathrm{~g}$ ) during polynya periods.

\subsection{Processes of Sediment Incorporation Into Sea Ice}

The determination of $Z_{f}$ (blue shade) and $Z_{S}$ (khaki shade) in Figure $4 \mathrm{~g}$ mainly relies on the characteristics of surface and bottom intensification of $S V$, respectively. Hence, for an overlap in signals from underwater frazil ice and resuspended sediment, a bin with the local minimum $S V$ should exist and its upper and lower adjacent bin would be $Z_{f}$ and $Z_{s}\left(Z-Z_{f}=2 \mathrm{~m}\right)$, respectively. Such overlap suggests favorable conditions for frazil ice to interact with resuspended sediment. Such conditions occurred at 10-25 $\mathrm{m}$ in depth on 17, 30, and 31 December and 16, 17, and 18 January as indicated by red bars in the upper part of Figure 4g. This finding indicates that suspension freezing can in fact occur in the coastal polynya.

As described in section 4.1, while transport of bottom sediments up into the near-surface layers is only an episodic event in winter, resuspension and dispersion up to $10 \mathrm{~m}$ above the seafloor occurred more frequently, caused by strong currents with the speeds $\geq 0.37 \mathrm{~m} / \mathrm{s}$. On the other hand, frazil ice frequently appeared in the water column from the surface down to 20- to 25-m depth during polynya episodes. This also allows for suspension freezing for regions shallower than $30 \mathrm{~m}$. Since the polynya in the Chukchi Sea is a typical Arctic coastal polynya, underwater interaction between frazil ice and resuspended sediment is considered to occur frequently as well in other Arctic polynyas for regions shallower than $30 \mathrm{~m}$ as long as strong currents occur. This is consistent with the result suggested by the model simulation by Smedsrud (2002). Hence, suspension freezing in such polynya and flaw lead regions is a major mechanism of sediment incorporation into sea ice.

According to Figures 3d, 3e, and 4g, supercooled water may descend down to 20-25 m, leading to frazil ice formation at depth. This circumstance implies the possibility of anchor ice formation on the seabed in polynya regions shallower than $25 \mathrm{~m}$. Once anchor ice lifts off from the seabed, it can be incorporated into the ice cover, taking larger amounts of sediment with it. As suggested from the field measurements (Darby et al., 2011; Mager et al., 2013), potentially this process also has an important role in sediment incorporation into sea ice. 
(a)

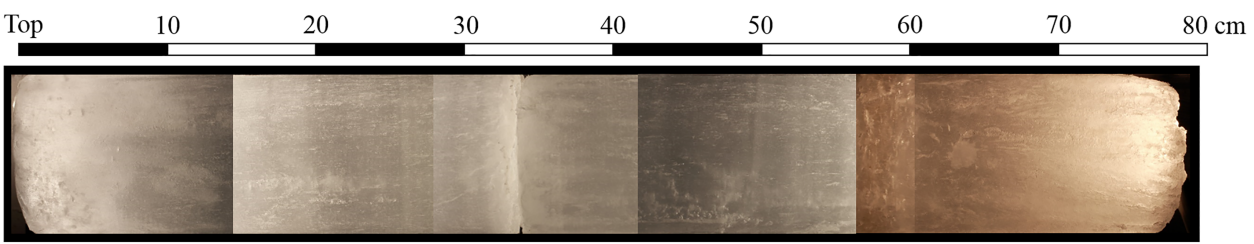

(b)

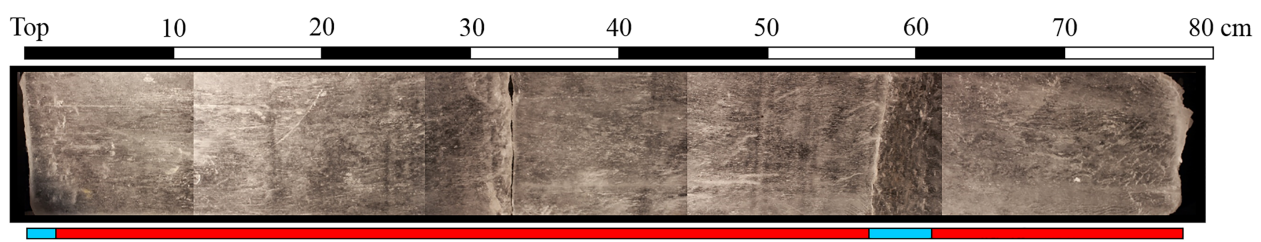

(c) 56
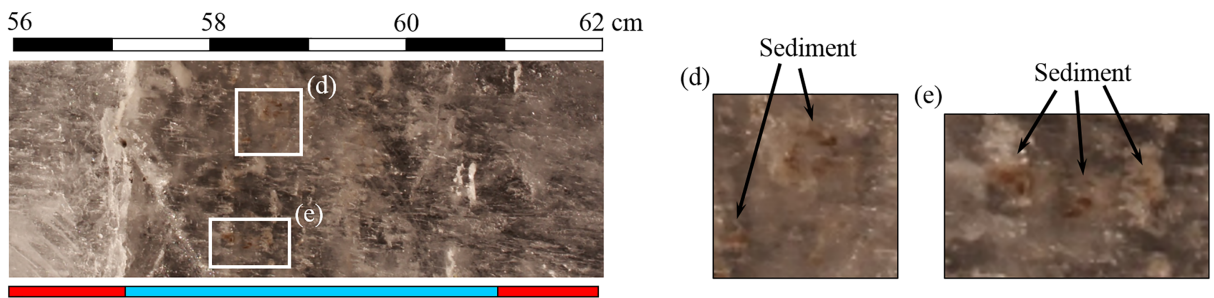

Figure 10. Photographs of (a) a landfast ice core obtained on 13 January 2015 and (b) vertical thick sections across its entire length. The top of the ice is toward the left. (c) The enlarged thick section for 56- to 62-cm in thickness. The sky blue and red bars in Figures 10b and 10c denote granular and columnar ice layers, respectively. (d and e) The enlarged thick section for the parts shown in Figure 10c. Arrows denote sediment inclusions.

The near-bottom current (in bin 1) reached $\sim 1 \mathrm{~m} / \mathrm{s}$, which corresponds to $u^{*}=2.6 \times 10^{-2} \mathrm{~m} / \mathrm{s}^{\prime}$ during polynya episodes (Figure 3g). Based on an analogous discussion in section 4.3, sediment particles with a grain size of $<210 \mu \mathrm{m}$ can be resuspended from the seafloor due to such strong currents. Anchor ice also likely captures large sediment particles directly on the seafloor without sediment resuspension. Hence, sea ice has the potential to incorporate sediment with large grain sizes $(D \sim$ the order of $100 \mu \mathrm{m})$, although sediment found inside sea ice is typically restricted to fine silt $(D<63 \mu \mathrm{m})$ and clay $(D<3.9 \mu \mathrm{m})$ (e.g., Darby et al., 2011). St John et al. (2015) found subrounded sediment with grain size of the order of $100 \mu \mathrm{m}$ encased by sea ice in the central Arctic Ocean. We suggest a possibility that those large sediment particles can be entrained into sea ice through suspension freezing and/or the process associated with anchor ice formation in coastal polynyas and subsequently transported to offshore regions due to sea ice drift. In paleo-oceanography, icebergs are generally regarded as the main means of transport of ice-rafted debris (IRD) characterized by the large grain sizes $(>63 \mu \mathrm{m})$. However, this study identifies an important role for sea ice as a source of IRD in addition to iceberg transport.

\subsection{The Process of Sediment Incorporation Into Sea Ice Estimated From Ice Core Analysis}

A sea ice core was extracted at $71.378^{\circ} \mathrm{N}, 156.556^{\circ} \mathrm{W}$ on the landfast ice northwest of Utqiagivik in the Chukchi Sea on 13 January 2015 (indicated by a blue triangle in Figure 1). This core site was located 13 $\mathrm{km}$ east northeast of the mooring site. The landfast ice containing the core site was mostly out of the range of the sea ice radar, except for its southwestern part. According to the radar imagery, landfast ice had been present continuously at this location since 24 November 2014 until the sampling day of 13 January 2015. Hence, we can infer the growth history of the landfast ice and sediment entrainment from a combination of ice stratigraphy, radar and mooring data, and ice thickness calculation.

Figure 10a shows a picture of the sea ice core. The total length of the core (= ice thickness) was $78 \mathrm{~cm}$. Vertical thick sections (Figure 10b) show that the ice cover was dominantly composed of columnar ice, with granular ice layers at 0 - to 2 - and $57-$ to $61-\mathrm{cm}$ depth. This ice stratigraphy suggests the following ice growth process. Frazil ice was first formed under turbulent conditions (granular ice), and then the ice grew thermally downward to $57 \mathrm{~cm}$ (columnar ice). After this, newly formed frazil ice was swept underneath the 


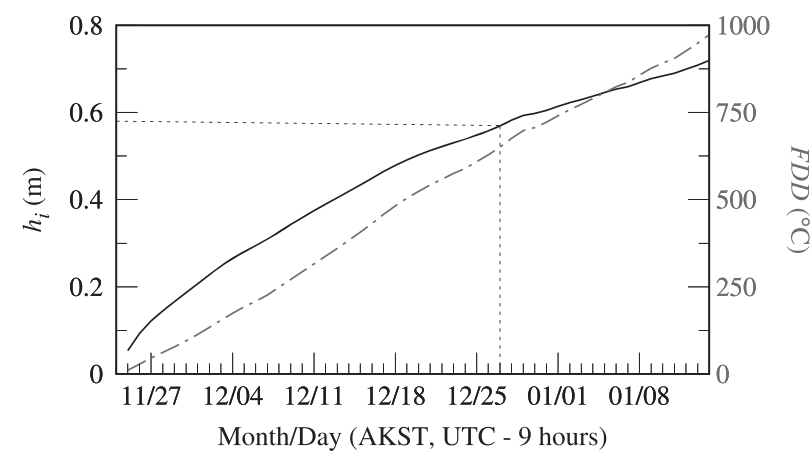

Figure 11. Time evolution of the freezing degree days (FDD: gray dashdotted curve) and estimated ice thickness (black curve) for the period from 24 November 2014 to 13 January 2015. The black dashed lines denote the timing when ice thickness reached $58 \mathrm{~cm}$. Time is expressed as local time (UTC, $9 \mathrm{~h}$ ), and tick marks correspond to 00:00 $\mathrm{h}$. existing landfast ice cover, consolidating into a layer of granular ice. This layer was capped by columnar ice growing downward below. Figures 10c10 e show that the granular ice layer at $57-$ to $61-\mathrm{cm}$ depth contained sediment. Other than at this depth, no other sediment inclusions were found in the core. Below, we estimate when this layer was formed and how sediment was incorporated.

The thermal growth of sea ice is parameterized using a freezing degree day model (FDD) (Maykut, 1986) as follows:

$$
\begin{gathered}
\mathrm{FDD}=\sum\left(T_{f}-T^{\prime}{ }_{a}\right), \\
h_{i}=1.33 \times \mathrm{FDD}^{0.58},
\end{gathered}
$$

where $T^{\prime}{ }_{a}$ is the daily mean air temperature and $T_{f}\left(=-1.9^{\circ} \mathrm{C}\right)$ is the freezing point. This method is useful to estimate ice thickness for the Arctic Ocean (e.g., Kaleschke et al., 2012; Yu \& Lindsay, 2003). Because the ice core of columnar ice down to $57 \mathrm{~cm}$ implies thermal growth, ice growth can be simulated using this method. For the 2014/2015 season, the onset of FDD is set on the first day when the radar showed the presence of the landfast ice (24 November). $T_{a}^{\prime}{ }_{a}$ is derived from daily averaged 2-m air temperature provided by the ERA-Interim. Figure 11 shows a time evolution of FDD and ice thickness $\left(h_{i}\right)$ estimated by equation (12) from 24 November 2014, indicating that ice thickness reached up to $57 \mathrm{~cm}$ on 27 December. On the other hand, the sea ice radar suggested the opening of polynya off Utqiagivik from 28 December owing to northwestward (offshore-ward) pack ice transport (Figure 3a). Based on ice stratigraphy, ice thickness estimation, and radar data, the landfast ice likely had grown thermally until this polynya formed and the granular ice layer of $57-61 \mathrm{~cm}$ (Figures 10b and 10c) originated from newly formed ice in the polynya between 28-29 December and/or 30 December to 3 January (Figure 3a). For these polynya episodes, frazil ice was detected from the ocean surface down to 15- to 25-m water depth around the mooring site (Figure $4 \mathrm{~g}$ ). The frazil ice would have consolidated into the granular ice. While we cannot determine the detailed processes of granular ice formation, it is highly likely that frazil ice was advected underneath landfast ice and subsequently consolidated there, rather than semiconsolidated ice being rafted underneath the landfast ice. During the polynya episodes, upward sediment transport was also detected (Figure 4g), and hence, underwater interaction between frazil ice and resuspended sediment was expected (Figure 4g). Along with the fact that sediment was contained within the granular ice layer of 57-61 cm, these findings support the sediment incorporation into sea ice through suspension freezing in the polynya.

For this study, we were not able to obtain data on grain size distribution of ice-entrained particles. In the future, such analysis is needed to understand the finer details of processes leading to sea ice sediment entrainment through suspension freezing.

\section{Concluding Remarks}

This study examines the process of sediment incorporation into sea ice based on the mooring data obtained in a coastal polynya in the northeastern Chukchi Sea. During coastal polynya episodes, underwater frazil ice associated with in situ and/or potential supercooling was detected from the surface down to 20- to 25-m water depth in ADCP acoustic backscatter data. In addition, upward dispersion of bottom sediments was observed during periods with current speeds $\geq \sim 0.4 \mathrm{~m} / \mathrm{s}$ from optical turbidity and ADCP backscatter data. During periods of strong currents, in particular, resuspended sediment was transported up into the nearsurface layer. These two events occurred simultaneously several times over winter, resulting in frazil ice and resuspended sediment particles appearing in the same water layer, fostering their interaction in the water column. This finding strongly supports the occurrence of suspension freezing in the coastal polynya system. Stratigraphic analysis of an ice core obtained on landfast ice northwest of Utqiagivik, and sediment inclusions in granular layers, also supports these processes. Although the resuspension and upward transport of sediment depends on the characteristics of the bottom sediment, our observations indicate that suspension freezing can frequently occur in Arctic polynyas at water depths shallower than $30 \mathrm{~m}$, provided 
bottom currents are strong. Hence, suspension freezing can be a major process for sediment incorporation into sea ice.

\section{Acknowledgments}

We thank UIC Science and CH2MHill Polar Services for planning and field support in mooring operations off Utqiagivik, and the North Slope Borough Department of Wildlife Management for the use of their boat and assistance from J. Craig George. The sea ice radar imageries were provided by the Geophysical Institute, University of Alaska Fairbanks (http:// feeder.gina.alaska.edu/). The ERAInterim product was provided by ECMWF (http:apps.ecmwf.int/ datasets/). The AMSR-E data were provided by the National Snow and Ice Data Center (NSIDC), University of Colorado (http://nsidc.org/data/). The sea ice production is calculated by Katsushi Iwamoto from AMSR-E data. The mooring data are available at https://ads.nipr.ac.jp/dataset/ A20150917-001 (Arctic Data Archive System). In Japan, support was provided by Grants-in-aid 17H01157 for science research and Arctic Challenge for Sustainability (ArCS) project from the Japanese Ministry of Education, Science, Sports, Culture and Technology and Global Station for Arctic Research, a project of Global Institution for Collaborative Research and Education at Hokkaido University. This study was partly supported by the Grant for Joint Research Program of the Japan Arctic Research Network Center and Arctic Challenge for Sustainability (ArCS) Program for Overseas Visit by Young Researchers.

\section{References}

Arrigo, K. R., \& McClain, C. R. (1994). Spring phytoplankton production in the western Ross Sea. Science, 266(5183), 261-263. https://doi. org/10.1126/science.266.5183.261

Arrigo, K. R., Perovich, D. K., Pickart, R. S., Brown, Z. W., van Dijken, G. L., Lowry, K. E., et al. (2014). Phytoplankton blooms beneath the sea ice in the Chukchi Sea. Deep Sea Research Part II: Topical Studies in Oceanography, 105, 1-16. https://doi.org/10.1016/j. dsr2.2014.03.018

Arrigo, K. R., Perovich, D. K., Pickart, R. S., Brown, Z. W., van Dijken, G. L., Lowry, K. E., et al. (2012). Massive phytoplankton blooms under Arctic sea ice. Science, 336(6087), 1408. https://doi.org/10.1126/science.1215065

Arrigo, K. R., \& van Dijken, G. L. (2004). Annual cycles of sea ice and phytoplankton in Cape Bathurst polynya, southeastern Beaufort Sea, Canadian Arctic. Geophysical Research Letters, 31, L08304. https://doi.org/10.1029/2003GL018978

Campbell, N. J., \& Collin, A. E. (1958). The discoloration of Foxe Basin ice. Journal of the Fisheries Research Board of Canada, 15(6), $1175-1188$.

Cooper, L. W., Larsen, I. L., Beasley, T. M., Dolvin, S. S., Grebmeier, J. M., Kelley, J. M., et al. (1998). The distribution of radiocesium and plutonium in sea ice-entrained Arctic sediments in relation to potential sources and sinks. Journal of Environmental Radioactivity, 39(3), 279-303. https://doi.org/10.1016/S0265-931X(97)00058-1

Darby, D. A., Myers, W. B., Jakobsson, M., \& Rigor, I. (2011). Modern dirty sea ice characteristics and sources: The role of anchor ice. Journal of Geophysical Research, 116, C09008. https://doi.org/10.1029/2010JC006675

Deines, K. L. (1999, March). Backscatter estimation using broadband acoustic Doppler current profilers. In Proceedings of the IEEE Sixth Working Conference on Current Measurement (Cat. No.99CH36331) (pp. 249-253). San Diego, Calif: IEEE. https://doi.org/10.1109/ CCM.1999.755249

Dethleff, D., \& Kuhlmann, G. (2009). Entrainment of fine-grained surface deposits into new ice in the southwestern Kara Sea, Siberian Arctic. Continental Shelf Research, 29(4), 691-701. https://doi.org/10.1016/j.csr.2008.11.009

Dethleff, D., \& Kuhlmann, G. (2010). Fram Strait sea-ice sediment provinces based on silt and clay compositions identify Siberian Kara and Laptev Seas as main source regions. Polar Research, 29(3), 265-282. https://doi.org/10.3402/polar.v29i3.6070

Dieckmann, G. S., Lange, M. A., Ackley, S. F., \& Jennings, J. C. (1991). The nutrient status in sea ice of the Weddell Sea during winter: Effects of sea ice texture and algae. Polar Biology, 11(7), 449-456. https://doi.org/10.1007/BF00233080

Dmitrenko, I. A., Kirillov, S. A., Tremblay, L. B., Bauch, D., Hölemann, J. A., Krumpen, T., et al. (2010). Impact of the Arctic Ocean Atlantic water layer on Siberian shelf hydrography. Journal of Geophysical Research, 115, C08010. https://doi.org/10.1029/2009JC006020

Downing, A., Thorne, P. D., \& Vincent, C. E. (1995). Backscattering from a suspension in the near field of a piston transducer. The Journal of the Acoustical Society of America, 97(3), 1614-1620. https://doi.org/10.1121/1.412100

Druckenmiller, M. L., Eicken, H., Johnson, M. A., Pringle, D. J., \& Williams, C. C. (2009). Toward an integrated coastal sea-ice observatory: System components and a case study at Barrow, Alaska. Cold Regions Science and Technology, 56(2-3), 61-72. https://doi.org/10.1016/j. coldregions.2008.12.003

Drucker, R., Martin, S., \& Moritz, R. (2003). Observations of ice thickness and frazil ice in the St. Lawrence Island polynya from satellite imagery, upward looking sonar, and salinity/temperature moorings. Journal of Geophysical Research, 108(C5), 3149. https://doi.org/ 10.1029/2001JC001213

Eicken, H., Gradinger, R., Gaylord, A., Mahoney, A. R., Rigor, I., \& Melling, H. (2005). Sediment transport by sea ice in the Chukchi and Beaufort Seas: Increasing importance due to changing ice conditions? Deep Sea Research Part II: Topical Studies in Oceanography, 52, 3281-3302. https://doi.org/10.1016/j.dsr2.2005.10.006

Eicken, H., Kolatschek, J., Freitag, J., Lindemann, F., Kassens, H., \& Dmitrenko, I. (2000). A key source and constraints on entrainment for basin-scale sediment transport by Arctic sea ice. Geophysical Research Letters, 27, 1919-1922. https://doi.org/10.1029/ 1999GL011132

Eicken, H., Reimnitz, E., Alexandrov, V., Martin, T., Kassens, H., \& Viehoff, T. (1997). Sea-ice processes in the Laptev Sea and their importance for sediment export. Continental Shelf Research, 17(2), 205-233. https://doi.org/10.1016/S0278-4343(96)00024-6

Fofonoff, N. P., \& Millard Jr, R. C. (1983). Algorithms for the computation of fundamental properties of seawater. UNESCO Tech. Pap. Mar. Sci., 44.

Fukamachi, Y., Simizu, D., Ohshima, K. I., Eicken, H., Mahoney, A. R., Iwamoto, K., et al. (2018). Sea-ice thickness in the coastal northeastern Chukchi Sea from moored ice-profiling sonar. Journal of Glaciology, 63(241), 888-891. https://doi.org/10.1017/jog.2017.56

Greenlaw, C. F. (1979). Acoustical estimation of zooplankton populations. Limnology and Oceanography, 24(2), 226-242. https://doi.org/ 10.4319/lo.1979.24.2.0226

Hirano, D., Fukamachi, Y., Ohshima, K. I., Watanabe, E., Mahoney, A. R., Eicken, H., et al. (2018). Winter water formation in coastal polynyas of the eastern Chukchi Shelf: Pacific and Atlantic influences. Journal of Geophysical Research: Oceans, 123, 5688-5705. https:// doi.org/10.1029/2017JC013307

Hirano, D., Fukamachi, Y., Watanabe, E., Ohshima, K. I., Iwamoto, K., Mahoney, A. R., et al. (2016). A wind-driven, hybrid latent and sensible heat coastal polynya off Barrow, Alaska. Journal of Geophysical Research: Oceans, 121, 980-997. https://doi.org/10.1002/ 2015JC011318

Hoitink, A. J. F. (2004). Tidally-induced clouds of suspended sediment connected to shallow-water coral reefs. Marine Geology, 208(1), 13-31. https://doi.org/10.1016/j.margeo.2004.04.021

Ito, M., Ohshima, K. I., Fukamachi, Y., Mizuta, G., Kusumoto, Y., \& Nishioka, J. (2017). Observations of frazil ice formation and upward sediment transport in the Sea of Okhotsk: A possible mechanism of iron supply to sea ice. Journal of Geophysical Research,: Oceans, 122 , 788-802. https://doi.org/10.1002/2016JC012198

Ito, M., Ohshima, K. I., Fukamachi, Y., Simizu, D., Iwamoto, K., Matsumura, Y., et al. (2015). Observations of supercooled water and frazil ice formation in an Arctic coastal polynya from moorings and satellite imagery. Annals of Glaciology, 56(69), 307-314. https://doi.org/ 10.3189/2015AoG69A839

Itoh, M., Shimada, K., Kamoshida, T., McLaughlin, F., Carmack, E., \& Nishino, S. (2012). Interannual variability of Pacific winter water inflow through Barrow Canyon from 2000 to 2006. Journal of Oceanography, 68(4), 575-592. https://doi.org/10.1007/s10872-012$0120-1$ 
Iwagaki, Y. (1956). (I) Hydrodynamical study on critical tractive force. Transactions. Japan Society of Civil Engineers, 1956(41), 1-21. https://doi.org/10.2208/jscej1949.1956.41_1

Iwamoto, K., Ohshima, K. I., \& Tamura, T. (2014). Improved mapping of sea ice production in the Arctic Ocean using AMSR-E thin ice thickness algorithm. Journal of Geophysical Research: Oceans, 119, 3574-3594. https://doi.org/10.1002/2013JC009749

Johnson, R. K. (1977). Sound scattering from a fluid sphere revisited. The Journal of the Acoustical Society of America, 61(2), 375-377. https://doi.org/10.1121/1.381326

Jones, J., Eicken, H., Mahoney, A., Rohith, M. V., Kambhamettu, C., Fukamachi, Y., et al. (2016). Landfast sea ice breakouts: Stabilizing ice features, oceanic and atmospheric forcing at Barrow, Alaska. Continental Shelf Research, 126, 50-63. https://doi.org/10.1016/j. csr.2016.07.015

Kaleschke, L., Tian-Kunze, X., Maaß, N., Mäkynen, M., \& Drusch, M. (2012). Sea ice thickness retrieval from SMOS brightness temperatures during the Arctic freeze-up period. Geophysical Research Letters, 39, L05501. https://doi.org/10.1029/2012GL050916

Kanna, N., Toyota, T., \& Nishioka, J. (2014). Iron and macro-nutrient concentrations in sea ice and their impact on the nutritional status of surface waters in the southern Okhotsk Sea. Progress in Oceanography, 126, 44-57. https://doi.org/10.1016/j.pocean.2014.04.012

Kempema, E. W., Reimnitz, E., Clayton, J. R. Jr., \& Payne, J. R. (1993). Interactions of frazil and anchor ice with sedimentary particles in a flume. Cold Regions Science and Technology, 21(2), 137-149. https://doi.org/10.1016/0165-232X(93)90003-Q

Lannuzel, D., Schoemann, V., De Jong, J., Pasquer, B., Van der Merwe, P., Masson, F., et al. (2010). Distribution of dissolved iron in Antarctic sea ice: Spatial, seasonal, and inter-annual variability. Journal of Geophysical Research, 115, G03022. https://doi.org/10.1029/ 2009JG001031

Lannuzel, D., van der Merwe, P. C., Townsend, A. T., \& Bowie, A. R. (2014). Size fractionation of iron, manganese and aluminium in Antarctic fast ice reveals a lithogenic origin and low iron solubility. Marine Chemistry, 161, 47-56. https://doi.org/10.1039/C3AY41312H

Leonard, G. H., Purdie, C. R., Langhorne, P. J., Haskell, T. G., Williams, M. J. M., \& Frew, R. D. (2006). Observations of platelet ice growth and oceanographic conditions during the winter of 2003 in McMurdo Sound, Antarctica. Journal of Geophysical Research, 111, C04012. https://doi.org/10.1029/2005JC002952

Mager, S. M., Smith, I. J., Kempema, E. W., Thomson, B. J., \& Leonard, G. H. (2013). Anchor ice in polar oceans. Progress in Physical Geography, 37(4), 468-483. https://doi.org/10.1177/0309133313479815

Mahoney, A., Eicken, H., Gaylord, A. G., \& Shapiro, L. (2007). Alaska landfast sea ice: Links with bathymetry and atmospheric circulation. Journal of Geophysical Research, 112, C02001. https://doi.org/10.1029/2006JC003559

Mahoney, A., Eicken, H., \& Shapiro, L. (2007). How fast is landfast sea ice? A study of the attachment and detachment of nearshore ice at Barrow, Alaska. Cold Regions Science and Technology, 47(3), 233-255. https://doi.org/10.1016/j.coldregions.2006.09.005

Mahoney, A. R., Eicken, H., Gaylord, A. G., \& Gens, R. (2014). Landfast sea ice extent in the Chukchi and Beaufort Seas: The annual cycle and decadal variability. Cold Regions Science and Technology, 103, 41-56. https://doi.org/10.1016/j.coldregions.2014.03.003

Martin, S. (1981). Frazil ice in rivers and oceans. Annual Review of Fluid Mechanics, 13(1), 379-397.

Martin, S., Drucker, R., Kwok, R., \& Holt, B. (2004). Estimation of the thin ice thickness and heat flux for the Chukchi Sea Alaskan coast polynya from Special Sensor Microwave/Imager data, 1990-2001. Journal of Geophysical Research, 109, C10012. https://doi.org/10.1029/ 2004JC002428

Martin, S., Drucker, R., Kwok, R., \& Holt, B. (2005). Improvements in the estimates of ice thickness and production in the Chukchi Sea polynyas derived from AMSR-E. Geophysical Research Letters, 32, L05505. https://doi.org/10.1029/2004GL022013

Martin, S., \& Kauffman, P. (1981). A field and laboratory study of wave damping by grease ice. Journal of Glaciology, 27(96), 283-313. https://doi.org/10.3189/S0022143000015392

Maykut, G. A. (1986). The surface heat and mass balance. In N. Untersteiner (Ed.), The Geophysics of Sea Ice NATO ASI Series (Series B: Physics), (). Boston, MA: Springer. https://doi.org/10.1007/978-1-4899-5352-0_6

Measures, C. I. (1999). The role of entrained sediments in sea ice in the distribution of aluminium and iron in the surface waters of the Arctic Ocean. Marine Chemistry, 68(1-2), 59-70. https://doi.org/10.1016/S0304-4203(99)00065-1

Mundy, C. J., Gosselin, M., Ehn, J., Gratton, Y., Rossnagel, A., Barber, D. G., et al. (2009). Contribution of under-ice primary production to an ice-edge upwelling phytoplankton bloom in the Canadian Beaufort Sea. Geophysical Research Letters, 36, L17601. https://doi.org/ 10.1029/2009GL038837

Mustapha, M. A., \& Saitoh, S. I. (2008). Observations of sea ice interannual variations and spring bloom occurrences at the Japanese scallop farming area in the Okhotsk Sea using satellite imageries. Estuarine, Coastal and Shelf Science, 77(4), 577-588. https://doi.org/10.1016/j. ecss.2007.10.021

Nihashi, S., Ohshima, K. I., \& Kimura, N. (2012). Creation of a heat and salt flux dataset associated with sea ice production and melting in the Sea of Okhotsk. Journal of Climate, 25(7), 2261-2278. https://doi.org/10.1175/JCLI-D-11-00022.1

Nürnberg, D., Wollenburg, I., Dethleff, D., Eicken, H., Kassens, H., Letzig, T., et al. (1994). Sediments in Arctic sea ice: Implications for entrainment, transport and release. Marine Geology, 119, 185-214. https://doi.org/10.1016/0025-3227(94)90181-3

Osterkamp, T. E., \& Gosink, J. P. (1984). Observations and analyses of sediment-laden sea ice. In P. W. Barnes, D. M. Schell, \& E. Reimnitz (Eds.), The Alaskan Beaufort Sea: Ecosystems and environments (pp. 73-93). Orlando, Fla: Academic Press.

Petrusevich, V., Dmitrenko, I. A., Kirillov, S. A., Rysgaard, S., Falk-Petersen, S., Barber, D. G., et al. (2016). Wintertime water dynamics and moonlight disruption of the acoustic backscatter diurnal signal in an ice-covered Northeast Greenland fjord. Journal of Geophysical Research: Oceans, 121, 4804-4818. https://doi.org/10.1002/2016JC011703

Pfirman, S. L., Eicken, H., Bauch, D., \& Weeks, W. F. (1995). The potential transport of pollutants by Arctic sea ice. Science of the Total Environment, 159(2-3), 129-146. https://doi.org/10.1016/0048-9697(95)04174-Y

Polyak, L., Alley, R. B., Andrews, J. T., Brigham-Grette, J., Cronin, T. M., Darby, D. A., et al. (2010). History of sea ice in the Arctic. Quaternary Science Reviews, 29(15-16), 1757-1778. https://doi.org/10.1016/j.quascirev.2010.02.010

Pope, N. D., Widdows, J., \& Brinsley, M. D. (2006). Estimation of bed shear stress using the turbulent kinetic energy approach-A comparison of annular flume and field data. Continental Shelf Research, 26(8), 959-970. https://doi.org/10.1016/j.csr.2006.02.010

Reimnitz, E., Clayton, J. R., Kempema, E. W., Payne, J. R., \& Weber, W. S. (1993). Interaction of rising frazil with suspended particles: Tank experiments with applications to nature. Cold Regions Science and Technology, 21(2), 117-135. https://doi.org/10.1016/0165232X(93)90002-P

Reimnitz, E., Marincovich, L. Jr., McCormick, M., \& Briggs, W. M. (1992). Suspension freezing of bottom sediment and biota in the Northwest Passage and implications for Arctic Ocean sedimentation. Canadian Journal of Earth Sciences, 29(4), 693-703. https://doi. org/10.1139/e92-060

Richard, M., Morse, B., Daly, S. F., \& Emond, J. (2011). Quantifying suspended frazil ice using multi-frequency underwater acoustic devices. River Research and Applications, 27(9), 1106-1117. https://doi.org/10.1002/rra.1446 
Rubey, W. W. (1933). Settling velocity of gravel, sand, and silt particles. American Journal of Science, 148, 325-338. https://doi.org/10.2475/ ajs.s5-25.148.325

Sakamoto, T., Ikehara, M., Aoki, K., Iijima, K., Kimura, N., Nakatsuka, T., \& Wakatsuchi, M. (2005). Ice-rafted debris (IRD)-based sea-ice expansion events during the past 100 kyrs in the Okhotsk Sea. Deep Sea Res. Part II: Topical Studies in Oceanography, 52(16-18), 2275-2301. https://doi.org/10.1016/j.dsr2.2005.08.007

Schott, F., Visbeck, M., \& Fischer, J. (1993). Observations of vertical currents and convection in the central Greenland Sea during the winter of 1988-1989. Journal of Geophysical Research, 98(C8), 14,401-14,421. https://doi.org/10.1029/93JC00658

Sedwick, P. N., \& DiTullio, G. R. (1997). Regulation of algal blooms in Antarctic shelf waters by the release of iron from melting sea ice. Geophysical Research Letters, 24(20), 2515-2518. https://doi.org/10.1029/97GL02596

Sherwood, C. R. (2000). Numerical model of frazil ice and suspended sediment concentrations and formation of sediment laden ice in the Kara Sea. Journal of Geophysical Research, 105(C6), 14,061-14,080. https://doi.org/10.1029/2000JC900037

Skogseth, R., Nilsen, F., \& Smedsrud, L. H. (2009). Supercooled water in an Arctic polynya: observations and modeling. Journal of Glaciology, 55(189), 43-52. https://doi.org/10.3189/002214309788608840

Smedsrud, L. H. (2001). Frazil-ice entrainment of sediment: Large-tank laboratory experiments. Journal of Glaciology, 47(158), 461-471. https://doi.org/10.3189/172756501781832142

Smedsrud, L. H. (2002). A model for entrainment of sediment into sea ice by aggregation between frazil-ice crystals and sediment grains Journal of Glaciology, 48(160), 51-61. https://doi.org/10.3189/172756502781831520

Smedsrud, L. H., \& Skogseth, R. (2006). Field measurements of Arctic grease ice properties and processes. Cold Regions Science and Technology, 44(3), 171-183. https://doi.org/10.1016/j.coldregions.2005.11.002

St John, K., Passchier, S., Tantillo, B., Darby, D., \& Kearns, L. (2015). Microfeatures of modern sea-ice-rafted sediment and implications for paleo-sea-ice reconstructions. Annals of Glaciology, 56(69), 83-93. https://doi.org/10.3189/2015AoG69A586

Stierle, A. P., \& Eicken, H. (2002). Sediment inclusions in Alaskan coastal sea ice: Spatial distribution, interannual variability, and entrainment requirements. Arctic, Antarctic, and Alpine Research, 34(4), 465-476. https://doi.org/10.1080/15230430.2002.12003518

Tamura, T., \& Ohshima, K. I. (2011). Mapping of sea ice production in the Arctic coastal polynyas. Journal of Geophysical Research, 116, C07030. https://doi.org/10.1029/2010JC006586

Tremblay, L. B., Schmidt, G. A., Pfirman, S., Newton, R., \& De Repentigny, P. (2015). Is ice-rafted sediment in a North Pole marine record evidence for perennial sea-ice cover? Philosophical Transactions of the Royal Society, A373. https://doi.org/10.1098/rsta.2014.0168

Ushio, S., \& Wakatsuchi, M. (1993). A laboratory study on supercooling and frazil ice production processes in winter coastal polynyas. Journal of Geophysical Research, 98(C11), 20,321-20,328. https://doi.org/10.1029/93JC01905

Yu, Y., \& Lindsay, R. W. (2003). Comparison of thin ice thickness distributions derived from RADARSAT Geophysical Processor System and advanced very high resolution radiometer data sets. Journal of Geophysical Research, 108(C12), 3387. https://doi.org/10.1029/ 2002JC001319 